\title{
Exoskeleton for Soldier Enhancement Systems Feasibility Study
}

\author{
John Jansen \\ Brad Richardson \\ Francois Pin \\ Randy Lind \\ Joe Birdwell
}

Oak Ridge National Laboratory

September 2000

Prepared by the

OAK RIDGE NATIONAL LABORATORY

Oak Ridge, Tennessee 37831

Managed by

UT-BATTELLE, LLC

For the

U.S. DEPARTMENT OF ENERGY

Under contract DE-AC05-OR22725

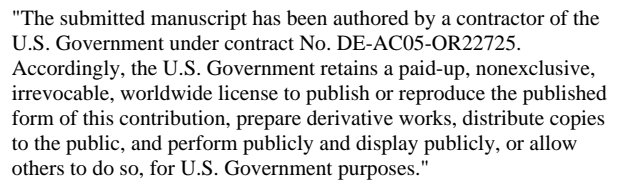




\section{Contents}

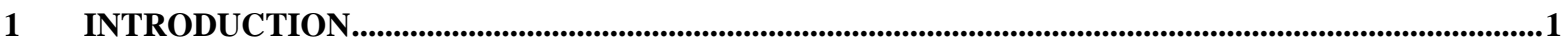

2 POWER AND ENERGY ...............................................................................................................

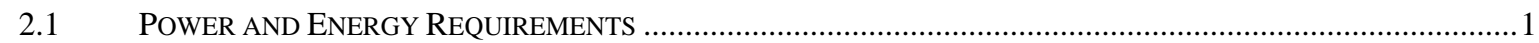

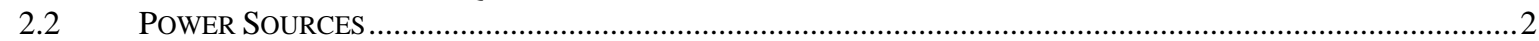

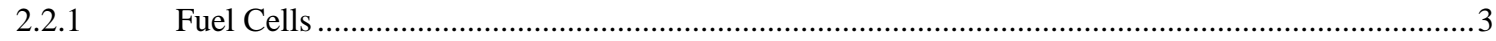

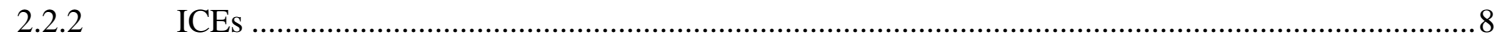

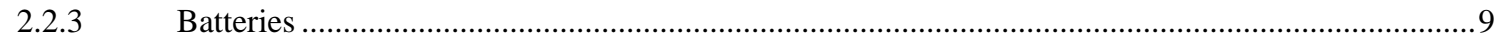

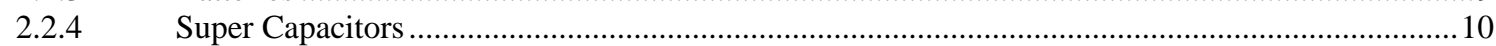

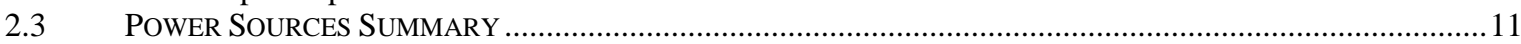

3 COMPARISON OF ACTUATORS …….....................................................................................................12

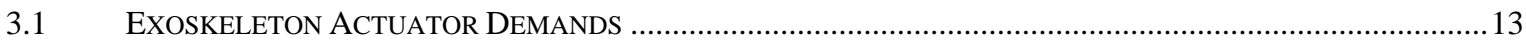

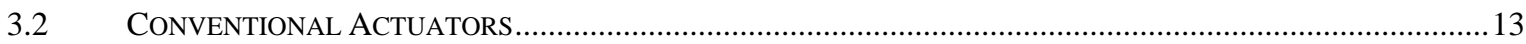

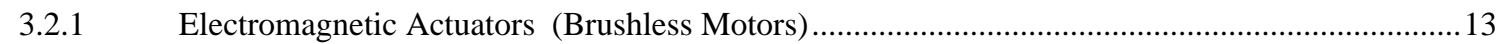

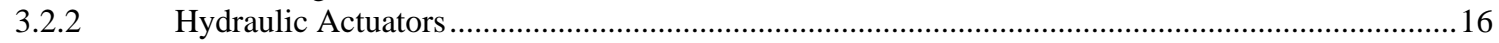

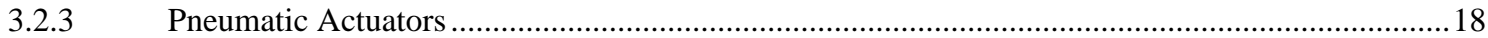

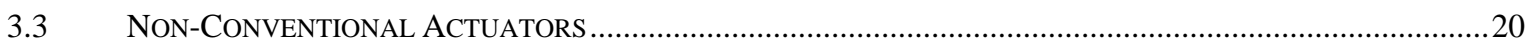

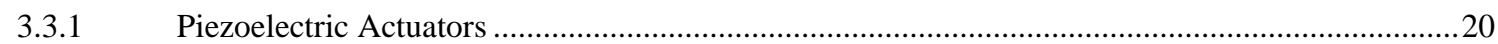

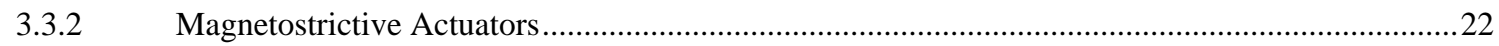

3.3.3 Shaped Memory Alloy (SMA) and Electroactive Polymers (EAP) ……..........................................22

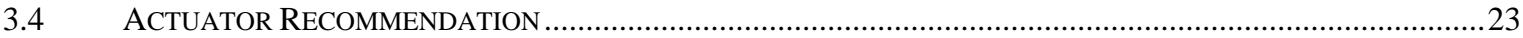

4 FUNDAMENTAL CONTROLS OBJECTIVES AND TOPOLOGY..........................................................24

5 SAFETY AND FAULT DETECTION CONCEPTS .......................................................................................28

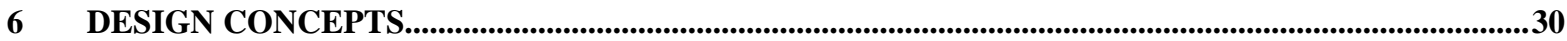

6.1 STRUCTURE

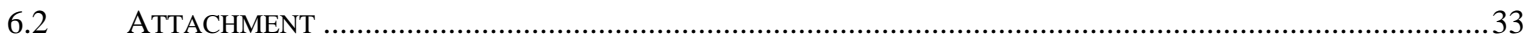

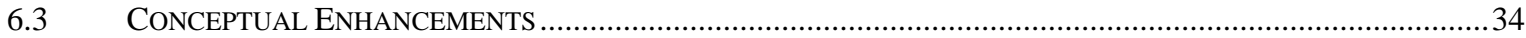

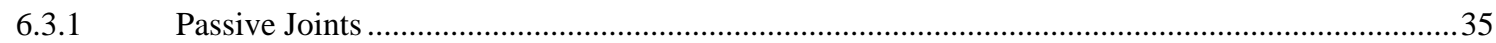

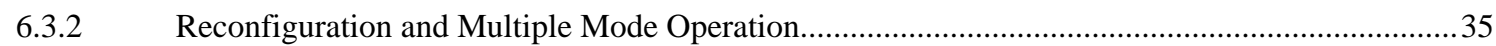

$7 \quad$ RECOMMENDATIONS.........................................................................................................................36

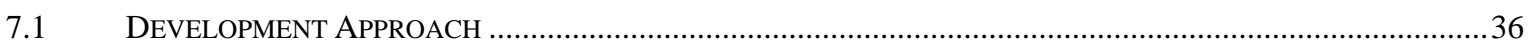

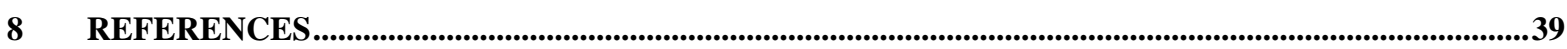




\section{Figures}

Fig. 1. Comparison of different power sources................................................................ 3

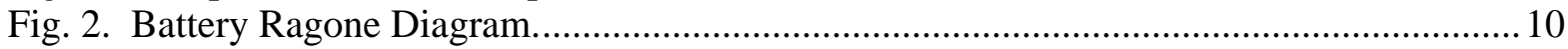

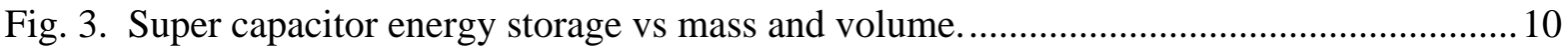

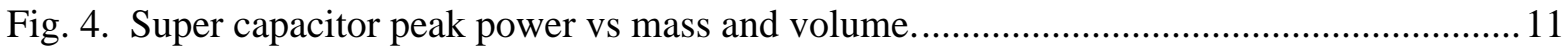

Fig. 5. Power vs mass for frameless brushless de motors.................................................... 14

Fig. 6. Torque per unit motor volume vs continuous power. ............................................... 14

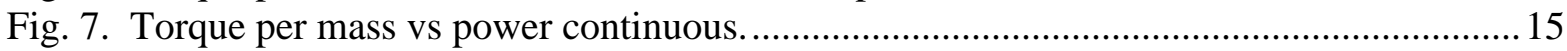

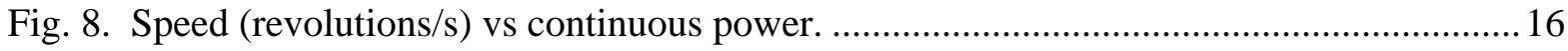

Fig. 9. Electromechanical model of piezoelectric actuator with mechanical load.....................2 21

Fig. 10. Magnetostrictive electromechanical model. ...........................................................22

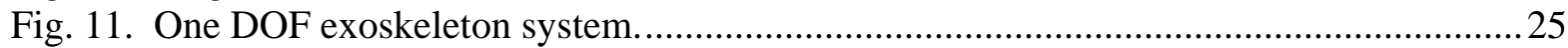

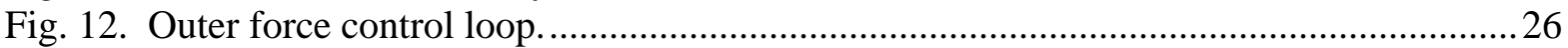

Fig. 13. Exoskeleton controller. ............................................................................................... 26

Fig. 14. NGMH fault detection (normal operation and sensor failure)...................................29

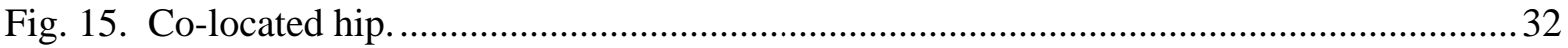

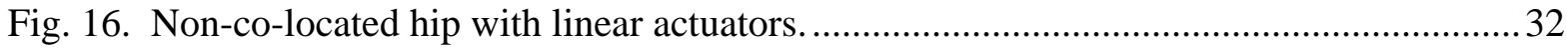

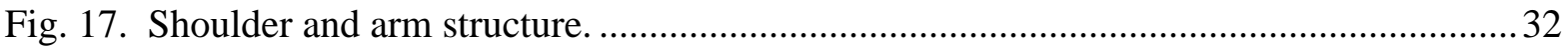

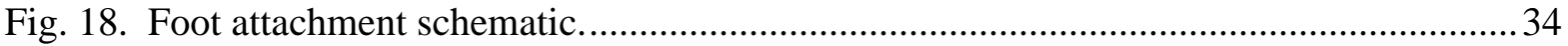

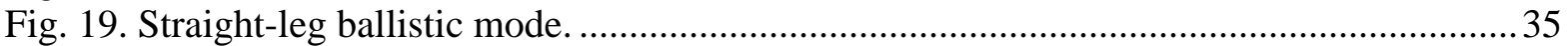

Fig. 20. Leg structure schematic demonstrating thigh prismatic joint. .................................... 36 


\section{INTRODUCTION}

The development of a successful exoskeleton for human performance augmentation (EHPA) will require a multi-disciplinary systems approach based upon sound biomechanics, power generation and actuation systems, controls technology, and operator interfaces. The ability to integrate key components into a system that enhances performance without impeding operator mobility is essential. The purpose of this study and report are to address the issue of feasibility of building a fieldable EHPA. Previous efforts, while demonstrating progress and enhancing knowledge, have not approached the level required for a fully functional, fieldable system. It is doubtless that the technologies required for a successful exoskeleton have advanced, and some of them significantly. The question to be addressed in this report is have they advanced to the point of making a system feasible in the next three to five years?

In this study, the key technologies required to successfully build an exoskeleton have been examined. The primary focus has been on the key technologies of power sources, actuators, and controls. Power sources, including internal combustion engines, fuel cells, batteries, super capacitors, and hybrid sources have been investigated and compared with respect to the exoskeleton application. Both conventional and non-conventional actuator technologies that could impact EHPA have been assessed. In addition to the current state of the art of actuators, the potential for near-term improvements using non-conventional actuators has also been addressed. Controls strategies, and their implication to the design approach, and the exoskeleton to soldier interface have also been investigated.

In addition to these key subsystems and technologies, this report addresses technical concepts and issues relating to an integrated design. A recommended approach, based on the results of the study is also presented.

\section{POWER AND ENERGY}

Issues relating to potential power sources and both steady-state and transient power requirements will be addressed. While no one power source can meet all the requirements optimally, a hybrid system that can satisfy both steady-state and transient power needs appears to be the most promising approach.

\subsection{Power and Energy Requirements}

To get a rough idea as to the power requirement of an exoskeleton, it is instructive to look at the power requirements of man-made and living vehicles (i.e., animals). Gabrielli and von Karman (Gabrielli, 1950) showed that specific resistance, $\varepsilon$, is an accurate measure of power requirement for a given velocity for a wide range of different types of mechanical locomotion including living organisms. Specific resistance is defined (using the same units used by Gabrielli) as

$$
\varepsilon=\frac{P}{W \cdot V}
$$


where $\mathrm{P}=$ power in units of $\mathrm{lb}-\mathrm{ft} / \mathrm{s}, \mathrm{W}=$ weight in $\mathrm{lb}$, and $\mathrm{V}=$ speed in $\mathrm{ft} / \mathrm{s}$. For a human being walking on level ground, the specific resistance is around 0.06 to 0.09 and increases to 0.12 when running. Bicycles, cars, and horses at low velocities have a specific resistance ranging from 0.01 to 0.05 . Since the specific resistance of an exoskeleton is not known, we will assume a conservative range from 0.01 to 0.1 . If the exoskeleton and its payload is $\mathrm{W}_{\mathrm{ex}}$ then the power requirement, $\mathrm{P}_{\mathrm{ex}}$, of such a machine must range from $\mathrm{P}_{\mathrm{ex}}=(.01 \text { to } 0.1)^{*} \mathrm{~W}_{\mathrm{ex}} \mathrm{V}_{\mathrm{ex}}$ where $\mathrm{V}_{\mathrm{ex}}$ is the velocity of the exoskeleton. At a speed of $2 \mathrm{~m} / \mathrm{s}$ (or $4.5 \mathrm{mph}$ or $6.6 \mathrm{ft} / \mathrm{s}$ ), $\mathrm{P}_{\mathrm{ex}}$ would range from 6.6 to $66 \mathrm{lb}-\mathrm{ft} / \mathrm{s}$ per $100 \mathrm{lb}$ of load (or 8.9 to $89 \mathrm{~W}$ per $100 \mathrm{lb}$ of load). For a $350 \mathrm{lb}$ total load (exoskeleton and payload), the upper power requirement is around $310 \mathrm{~W}$. Standard earthmoving equipment has a payload to weight ratio of $1: 2$, which implies a conventional hydraulic system and would suggest an exoskeleton weight of approximately $233 \mathrm{lb}$ and a payload of $117 \mathrm{lb}$. Based on anticipated performance improvements of an exoskeleton in comparison to heavy equipment, the payload to weight ratio is expected to be significantly better.

Two cases will be compared, walking while lifting $100 \mathrm{lb}$ and running. If in addition to walking, the power required to lift $100 \mathrm{lb}$ vertically against gravity at $1 \mathrm{ft} / \mathrm{s}$ is added, the additional power is around $140 \mathrm{~W}$. Thus, for an exoskeleton with maximum payload, the total power required could be expected to around $440 \mathrm{~W}$, assuming a worst-case scenario and extrapolating the same power requirements as those for a human. The second case is running. As mentioned above, about $310 \mathrm{~W}$ were calculated assuming a speed of $2 \mathrm{~m} / \mathrm{s}(4.5 \mathrm{mph})$. Increasing the speed to $3 \mathrm{~m} / \mathrm{s}(6.7 \mathrm{mph})$ and the specific resistance range to 0.01 to 0.12 for running, similarly, gives an estimate of approximately $560 \mathrm{~W}$. Based on these two scenarios, $600 \mathrm{~W}$ should be a conservative upper bound for the required steady-state power. Peak power demands could be significantly larger than $600 \mathrm{~W}$ and would affect the overall sizing of the power supply, unless temporary energy storage is used to offset peak power demands. For motions such as rapid, deep, knee bends, or climbing stairs, peak power demands could reach as high as $2 \mathrm{~kW}$. It is clear that an exoskeleton power source will have to have both large energy (600 W times operational hours) and peak-power $(2 \mathrm{~kW},>3$ times the nominal load) capacities.

\subsection{Power Sources}

As discussed above, there could be significant differences in the steady-state power requirements and the peak power or transient demands. The power source must, therefore, be able to meet both the energy requirements and peak power demands and comparison of potential power sources must be made with respect to meeting both of these requirements. For an exoskeleton type of system, the specific power (power $\div$ weight) and specific energy (energy $\div$ weight) are the parameters that are more useful for comparison of potential power systems. Ragone Diagrams (Fig. 1), which plot specific energy vs specific power, provides a means for making broad, general, comparisons between potential power sources. However, it should be noted that Ragone Diagrams provide information on steady-state specific power and specific energy, but they do not provide any indication as to the response time of a power source and thus, its ability to follow demand.

Figure 1 provides a general comparison of typical fuel cells, batteries, internal combustion engines, and super capacitors. It should be noted that on-going research is continuing to expand the capabilities of these power sources. Although other power sources and storage devices, (e.g., compressed gas, thermoelectric devices, and flywheels) are available, they are not 
considered practical for a remote mobile device, such as an exoskeleton. From Fig. 1, it can be seen that (1) internal combustion engines have relatively high specific power and specific energy and (2) a hybrid system such as a fuel cell and either batteries or super capacitors can also meet the requirement of high specific power and energy. Using a single power source requires sizing the source such that it can meet both steady-state energy needs and peak power loads. For systems such as the exoskeleton, where peak loads can be several times the steady-state loads, this may result in an oversized source (both weight and cube) and a significant reduction in efficiency. Alternatively, a hybrid system can handle large variations in steady-state and peak loads, as one source is sized to provide for power peaks and another to provide steady-state energy. A hybrid system offers the possibility of a more efficient system, optimized for both peak power and steady-state energy needs at the cost of increased complexity. In the following section, potential power sources will be discussed with regard to the exoskeleton specific requirements.

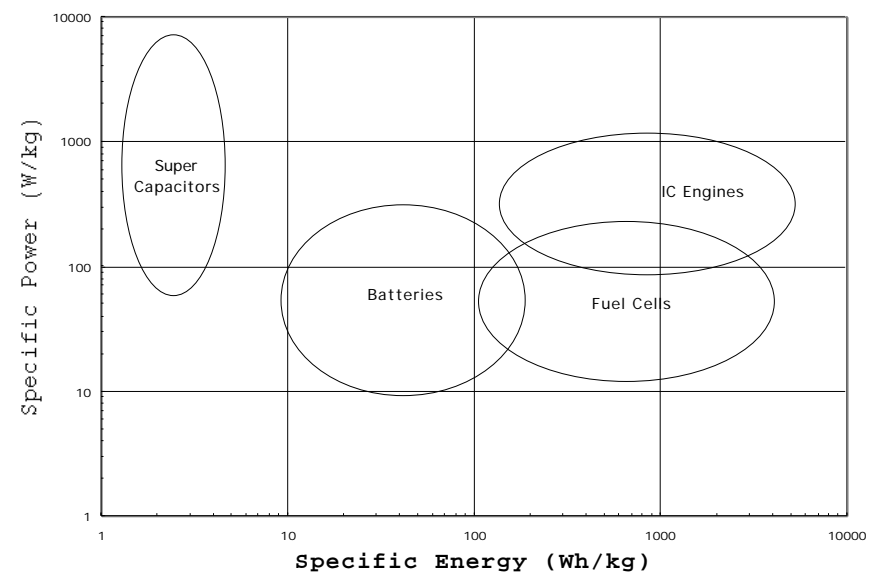

Fig. 1. Comparison of different power sources.

\subsubsection{Fuel Cells}

The National Aeronautics and Space Administration (NASA) demonstrated the potential of fuel cells, originally discovered in 1839 , by using them to provide power during space flights in the 1960s. Since then, research has been on going with a focus on improving efficiency and economic viability. There are multiple types of fuel cells, typically designated by the electrolyte type, currently in various stages of development (Table 1). These include polymer electrolyte membrane (PEM), alkaline (AFC), phosphoric acid (PAFC), molten carbonate (MCFC), and solid oxide (SOFC). Each has different characteristics and is suited to particular applications. MCFCs and SOFCs operate between 600 and $1000^{\circ} \mathrm{C}$ and thus, are not suitable for applications that require close proximity to a human operator. PAFCs, which use concentrated phosphoric acid (up to 100\%) for the electrolyte, can operate in temperature ranges from 150 to $220{ }^{\circ} \mathrm{C}$, but are poor ionic conductors, susceptible to carbon monoxide (CO) poisoning at the lower temperature range, and also have low power to weight ratios (Hirschenhofer, 1999). AFCs, which operate in the 90 to $100{ }^{\circ} \mathrm{C}$ range, have been limited to military and space applications due to the expense of removing carbon dioxide $\left(\mathrm{CO}_{2}\right)$ from the fuel and air streams and are generally 
being phased out (Thomas, 1999). PEM fuel cells have a relatively low operating temperature (about $80^{\circ} \mathrm{C}$ ) and are the most appropriate for portable applications in close proximity to an operator.

Table 1. Comparison of fuel cell types.

Sources: Hirschenhofer, 1999 and Thomas, 1999

\begin{tabular}{|l|l|c|l|}
\hline Fuel Cell Type & \multicolumn{1}{|c|}{ Electrolyte } & $\begin{array}{c}\text { Operating } \\
\text { Temperature }\left({ }^{\circ} \mathrm{C}\right)\end{array}$ & \multicolumn{1}{|c|}{ Comments } \\
\hline Alkaline (AFC) & $\begin{array}{l}\text { Aqueous solution of potassium } \\
\text { hydroxide soaked in a matrix }\end{array}$ & $90-100$ & $\begin{array}{l}\text { Expensive removal of } \mathrm{CO}_{2} \\
\text { required. High performance. }\end{array}$ \\
\hline $\begin{array}{l}\text { Phosphoric Acid } \\
(\text { PAFC) }\end{array}$ & $\begin{array}{l}\text { Immobilized liquid phosphoric } \\
\text { acid }\end{array}$ & $175-205$ & $\begin{array}{l}\text { Low power/weight and } \\
\text { power/vol. High efficiency. } \\
\text { Tolerant of fuel impurities. }\end{array}$ \\
\hline $\begin{array}{l}\text { Polymer } \\
\text { Electrolyte } \\
\text { Membrane (PEM) }\end{array}$ & Ion exchange membrane & $60-100$ & $\begin{array}{l}\text { Low temperatures. Quick } \\
\text { startup. Sensitive to fuel } \\
\text { impurities. }\end{array}$ \\
\hline $\begin{array}{l}\text { Molten Carbonate } \\
\text { (MCFC) }\end{array}$ & $\begin{array}{l}\text { Immobilized liquid molten } \\
\text { carbonate }\end{array}$ & $600-1000$ & $\begin{array}{l}\text { High temperatures lead to } \\
\text { corrosion and cell breakdown. } \\
\text { High temperature results in } \\
\text { higher efficiency, inexpensive } \\
\text { catalysts, more fuel options. }\end{array}$ \\
\hline $\begin{array}{l}\text { Solid Oxide } \\
\text { (SOFC) }\end{array}$ & $\begin{array}{l}\text { Ceramic (zirconium oxide } \\
\text { based) }\end{array}$ & $800-1000$ & \\
\hline
\end{tabular}

While internal combustion engines (ICEs) have superior steady-state specific power, fuel cells are more human-compatible when noise and waste by-products are considered. In particular, PEM fuel cells operate at low temperatures with water as the waste by-product. The PEM fuel cells, however, require careful water management and a particularly clean source of hydrogen (essentially $\mathrm{CO}$ and $\mathrm{CO}_{2}$ free). These fuel cells are susceptible to $\mathrm{CO}$ poisoning, which adversely affects the fuel cell voltage, especially at higher current densities (Hirschenhofer, 1999). A major focus of research and development (R\&D) with respect to fuel cells is related to reformer technology, which is being developed to extract hydrogen from hydrocarbon fuels. Significant progress has been made in research concerned with direct methanol PEM fuel cells, which use the methanol directly without going through a reformer. However, the power density of direct methanol PEMs still lags that of hydrogen/air PEMs due to the need for significantly more of the expensive platinum catalyst (in comparison to hydrogen/air PEMs), and the loss of performance caused by methanol "crossover" (Thomas, 1999). A potential clean source of hydrogen for a PEM is chemical reactions, which are similar to commercially available systems based on a single exothermic sodium hydroxide reaction. The water generated at the fuel cell reaction can be recycled for use in the hydrogen generation, to reduce weight and further increase efficiency.

Commercially available fuel cells in the $500 \mathrm{~W}$ to $2 \mathrm{~kW}$ range can have specific powers on the order of 50 to $150 \mathrm{~W} / \mathrm{kg}$ (Ballard and Analytic Power Corporation). AeroVironment, Inc., has developed custom fuel cells for remote power applications in the same range, with specific powers of $675 \mathrm{~W} / \mathrm{kg}$ for the cells only and on the order of $225 \mathrm{~W} / \mathrm{kg}$ including ancillary support equipment. The specific power is comparable to that for batteries and below that for super capacitors and internal combustion engines. The overall specific energy of the fuel cell system is 
highly dependent upon the generating system for hydrogen, which has a specific energy (higher heating value) of $40 \mathrm{kWh} / \mathrm{kg}$.

Chemical reactions as a means to generate a suitable supply of hydrogen for a fuel cell have been examined. Three types of hydrogen-releasing chemical processes have been evaluated as means for feeding a fuel cell that would power an exoskeleton. These processes are the reaction of pure elements (alkali metals, alkaline earth elements, etc.) with water, reaction of alkali and alkaline earth hydrides with water, and the decomposition of metal hydrides. The methods considered are summarized and compared and the relative advantages and disadvantages of each with regard to the proposed application discussed.

\section{Alkali and Alkaline Earth/Water Reactions}

The reactions of alkali elements (specifically lithium, sodium, and potassium) with water are rapid, irreversible, and highly exothermic. The general form of the reaction is

$$
2 \mathrm{M}+2 \mathrm{H}_{2} \mathrm{O} \rightarrow 2 \mathrm{MOH}+\mathrm{H}_{2}
$$

As the reactions are irreversible, the rate cannot be altered by controlling the concentration (or the pressure) of the products. The rate of hydrogen generation may be controlled by the rate at which either or both of the reactants are added to the reaction vessel. However, controlling alkali-water reactions by controlling the rate of water addition is impracticable because the amount of heat generated per mass of water added is more than sufficient to increase the temperature of the product to the boiling point of the hydroxide. It is preferable to control hydrogen generation by limiting the rate at which the alkali is introduced to (or comes into contact with) water. Because of the reactivity of alkali elements with water, it is essential that these alkalis be kept in a moisture-free environment before their use. Because of their inflammability, it is also essential that the heat generated by the reaction be removed efficiently.

The primary advantage of alkali-water reactions for hydrogen generation is the relatively low mass of reactants required per mass of hydrogen released, particularly when lithium and water are reacted. Much of this advantage is lost if a large excess of water is needed to effect heat removal from the process. Other advantages of alkali-water reactions are the complete conversion of reactants and a high rate of reaction. In addition to exothermicity, the disadvantages of these reactions include chemical instability of the reactants, difficulty in regenerating the reactants for reuse, and formation of a corrosive (caustic) by-product.

In addition to alkali elements, reactions of alkaline earth elements (calcium, magnesium, etc.) with water have been considered. These reactions take place less rapidly than do alkali-water reactions and they produce somewhat less corrosive bases. However, the mass of reactants required per mass of hydrogen produced is increased over the alkali-water case, because of the need for two molecules of water per atom of alkaline earth element. As with alkali/water reactions, alkaline earth/water reactions are highly exothermic (Table 2). 
Table 2. Comparison of hydrogen-generating chemical reactions.

\begin{tabular}{|c|c|c|c|}
\hline Reaction & $\begin{array}{c}\Delta \mathrm{H}_{\mathrm{rxn}, 298 \mathrm{~K}}, \\
\quad \mathrm{kcal}\end{array}$ & $\begin{array}{c}\Delta \mathrm{H}_{\mathrm{rxn}, 298 \mathrm{~K}} \\
\mathrm{kcal} / \mathrm{gmol} \mathrm{H}_{2}\end{array}$ & $\begin{array}{l}\text { Mass Ratio } \\
\text { Reactants: } \mathrm{H}_{2}\end{array}$ \\
\hline $2 \mathrm{Na}+2 \mathrm{H}_{2} \mathrm{O} \rightarrow 2 \mathrm{NaOH}+\mathrm{H}_{2}$ & -87.78 & -87.78 & 40.7 \\
\hline $2 \mathrm{Li}+2 \mathrm{H}_{2} \mathrm{O} \rightarrow 2 \mathrm{LiOH}+\mathrm{H}_{2}$ & -106.38 & -106.38 & 24.8 \\
\hline $\mathrm{Ca}+2 \mathrm{H}_{2} \mathrm{O} \rightarrow \mathrm{Ca}(\mathrm{OH})_{2}+\mathrm{H}_{2}$ & -103.04 & -103.04 & 37.8 \\
\hline $\mathrm{NaH}+\mathrm{H}_{2} \mathrm{O} \rightarrow \mathrm{NaOH}+\mathrm{H}_{2}$ & -30.22 & -30.22 & 20.8 \\
\hline $\mathrm{LiH}+\mathrm{H}_{2} \mathrm{O} \rightarrow \mathrm{LiOH}+\mathrm{H}_{2}$ & -31.65 & -31.65 & 12.9 \\
\hline $\mathrm{CaH}_{2}+2 \mathrm{H}_{2} \mathrm{O} \rightarrow \mathrm{Ca}(\mathrm{OH})_{2}+2 \mathrm{H}_{2}$ & -57.94 & -28.97 & 19.4 \\
\hline $\mathrm{B}_{2} \mathrm{H}_{6}+6 \mathrm{H}_{2} \mathrm{O} \rightarrow 2 \mathrm{~B}(\mathrm{OH})_{3}+6 \mathrm{H}_{2}$ & -107.98 & -18.00 & 11.2 \\
\hline $\mathrm{NaBH}_{4}(a q)+2 \mathrm{H}_{2} \mathrm{O} \rightarrow \mathrm{NaBO}_{2}(a q)+4 \mathrm{H}_{2}$ & $\begin{array}{l}\text { Data not }{ }^{a} \\
\text { available }\end{array}$ & $\begin{array}{l}\text { Data not } \\
\text { available }\end{array}$ & $18.77^{b}$ \\
\hline $\mathrm{NaBH}_{4}+2 \mathrm{H}_{2} \mathrm{O} \rightarrow \mathrm{NaBO}_{2}(a q)+4 \mathrm{H}_{2}$ & -46.68 & -11.67 & $9.16^{c}$ \\
\hline $2 \mathrm{LiH} \leftrightarrow \mathrm{Li}+\mathrm{H}_{2}$ & 43.2 & 43.2 & 7.9 \\
\hline $\mathrm{CaH}_{2} \leftrightarrow \mathrm{Ca}+2 \mathrm{H}_{2}$ & 45.1 & 22.6 & 10.4 \\
\hline $\mathrm{TiFeH}_{1.7} \leftrightarrow \mathrm{TiFe}+0.85 \mathrm{H}_{2}$ & 6.5 & 7.6 & 61.5 \\
\hline
\end{tabular}

${ }^{a}$ Enthalpy data for sodium borohydride were not available for the analysis. It is expected that the heat released per g-mole of hydrogen produced will be approximately equal to that released by the hydrolysis of crystalline $\mathrm{NaBH}_{4}$.

${ }^{b}$ Mass ratio assumes that water consumed by the hydrolysis reaction is not replenished.

${ }^{c}$ Mass ratio is based on the necessary replenishment of water consumed by the reaction.

Hydrolysis of Binary Hydride and Tertiary Hydrides

Hydrogen is generated by the reaction of binary hydrides with water according to the general reaction

$$
\mathrm{MH}_{\mathrm{x}}+\mathrm{xH}_{2} \mathrm{O} \rightarrow \mathrm{M}(\mathrm{OH})_{\mathrm{x}}+x \mathrm{H}_{2}
$$

where " $x$ " is the valence of the cation. Reactions of the hydrides of lithium, sodium, calcium, and boron have been considered for the proposed application.

As Eq. (3) indicates, the reactions of alkali and alkaline earth hydrides with water occur irreversibly, and they result in the release of hydrogen and the formation of a hydroxide. 
Relative to the hydrolysis reactions of pure alkalis and alkaline earths, the hydrolysis reactions of binary hydride release less energy per unit of hydrogen released and requires less reactant mass per mass of hydrogen released.

In addition to alkali and alkaline hydride reactions, the reaction of diborane $\left(\mathrm{B}_{2} \mathrm{H}_{6}\right)$ with water was evaluated. The hydrolysis of diborane has the advantages of relatively low heat generation and a low mass ratio of reactants-to-hydrogen-generated. The physical state of diborane (a gas at ambient conditions) is both an advantage and a major disadvantage. Control of hydrogen generation by diborane hydrolysis can be accomplished by metering the flow of reactant gas through a water-containing vessel. However, producing hydrogen in a compact processing system would require storage of diborane at high pressure.

The hydrolysis reaction of the tertiary hydride sodium borohydride $\left(\mathrm{NaBH}_{4}\right)$ has been considered based on information obtained from the Millennium Cell Company (MCC). MCC has developed a process in which the hydride (in aqueous solution) is hydrolyzed in the presence of a metal catalyst (e.g., ruthenium, nickel, and cobalt) (Amendola, 2000). The results of development work by MCC indicate (a) that the rate of hydrogen generation from the $\mathrm{NaBH}_{4}$ process far exceeds that required to power an exoskeleton and (b) that the rate of $\mathrm{H}_{2}$ generation decreases with increasing borate concentration. MCC recommends that a low percentage of sodium hydroxide be placed in the aqueous feed solution to suppress slow hydrolysis before the introduction of the catalyst.

The use of an aqueous feed solution during the MCC process simplifies control of the reaction rate and provides a heat transfer medium. Using a 25 weight $\%$ feed solution (containing $\mathrm{NaOH}$ at 1 weight \%), the total mass of the initial feed solution charge required to generate $1 \mathrm{lb}$ of hydrogen is $18.77 \mathrm{lb}$. The rate of generation will not remain constant because of disproportionate (by weight) depletion of sodium borohydride and water during the reaction.

To minimize the mass of reactants, the MCC process could be modified so that the solid $\mathrm{NaBH}_{4}$ is blended with water on demand, using water recycled from the fuel cell. The effect on the rate of hydrogen generation is unknown, as is the effect on the rate control scheme. In addition, no heat sink for removal of the heat generated by the reaction is present. This may be a significant problem, as the heat released during the production of one pound of hydrogen from the solid borate is approximately equal to that required to vaporize $11 \mathrm{lb}$ of water at ambient conditions.

\section{Metal Hydride Decomposition}

Thermal decomposition of metal hydrides is the most commonly used means of hydrogen release from a chemical storage medium. Decomposition reactions are reversible and endothermic. Consequently, terminating the input of heat to the process can stop the reaction. Adjusting the rate of heat input or the hydrogen pressure can control the rate of hydrogen released over the process. Furthermore, the density of hydrogen stored on metal substrates is greater than the density of pure, liquid hydrogen.

Binary hydrides are not generally suitable for on-demand release because of their thermal stability. For example, hydrides of lithium, sodium, and calcium release hydrogen at significant 
pressures (i.e., $1 \mathrm{~atm}$ ) only at temperatures in excess of $300^{\circ} \mathrm{C}$. Transition metal and rare-earth alloy hydrides are better suited for hydrogen release applications since hydrogen is released effectively at temperatures slightly above ambient. As a rule of thumb, in order for hydrogen to be released at $1 \mathrm{~atm}$ pressure and at a temperature of about $27^{\circ} \mathrm{C}$, the heat of decomposition should be $9 \mathrm{kcal} / \mathrm{gmole}$ for $\mathrm{H}_{2}$. Of the hydride substrates developed for fuel cell applications, the titanium-iron substrate has undergone the most development. The hydride:hydrogen mass ratio for the $\mathrm{TiFeH}_{1.7}$ hydride is about 61 .

From a mass conservation standpoint, the hydrolysis of $\mathrm{NaBH}_{4}$ is the most attractive option for hydrogen generation. Generation of $1 \mathrm{lb}$ of hydrogen will consume $9.16 \mathrm{lb}$ of sodium borohydride. At a hydrogen production rate of $1 \mathrm{lb} / 8 \mathrm{~h}$, heat will be generated at a rate of $1,303 \mathrm{Btu} / \mathrm{h}$.

From a safety standpoint, decomposition of a transition metal hydride (probably a TiFe alloy) is the best option for generating the needed hydrogen. However, the mass of substrate required to support $1 \mathrm{lb}$ of hydrogen may be too great for the exoskeleton application.

Of the individual hydrogen mechanisms considered, no single reaction appears to meet the need for hydrogen generation at a rate of $0.125 \mathrm{lb} / \mathrm{h}(1 \mathrm{lb}$ over an 8 -h period) without presenting significant engineering challenges. The hydrolysis reactions would require design of a compact, low-weight, heat-transfer system to remove the heat produced by reaction and with the exception of the catalytic reaction of sodium borohydride, will result in the gradual build-up of a corrosive hydroxide solution. This corrosive hydroxide solution will eventually have to be disposed of or neutralized.

In addition to the single-step processes evaluated, a two-step operation has been considered in which calcium hydride is hydrolyzed and the hydroxide is then neutralized with nitric acid. The combined heat generated per gram mole of hydrogen generated is $32.96 \mathrm{kcal}$. The ratio of reactant-to-hydrogen mass is 66.3. Based on the heat released and the mass ratio, this approach is less favorable than decomposition of a transition metal hydride.

\subsubsection{ICEs}

In general, ICEs are more efficient when the overall energy output is high in comparison to the power output-in other words, the weight of the fuel is high in comparison to the weight of the engine. Although this is not the case for the exoskeleton application, ICEs are still an option worthy of consideration. Reciprocal diesel engines and turbines, in particular, will be discussed. While new developments are currently being pursued for both small diesel and turbines, which will increase their attractiveness for an exoskeleton application, noise, heat, and emissions remain issues that must be confronted, generally at the expense of increased weight. Gasoline engines, which are more readily available in the 1 to $2 \mathrm{~kW}$ range, were not considered a viable alternative for a fieldable system due to the hazards associated with gasoline.

The power density of 1 to $40 \mathrm{~kW}$ diesel engines typically range from 100 to $400 \mathrm{~W} / \mathrm{kg}$, with fuel consumption in the 200 to $300 \mathrm{~g} / \mathrm{kWh}$ range (Theis, 2000; Heywood, 1988). Fuel consumption is generally increased in smaller scale diesel engines and generators. There are few diesel engines available in the lower power ranges. While a company called D-Star Engineering 
Corporation is currently making smaller scale diesels and is planning a $1 \mathrm{~kW}$ engine and generator set, it is doubtful that these will be available within the next one to two years.

In general, turbine fuel consumption would be anticipated to be from 5 to $15 \%$ less efficient than that for reciprocating diesels (Andriulli, 1999; Heywood, 1988). Micro-turbine performance does not scale well below $25 \mathrm{~kW}$ and fuel consumption tends to increase more in comparison to piston engines at partial loads (Andriulli, 1999). However, there are micro and mesoscopic turbine generators currently being developed under Defense Advanced Research Projects Agency (DARPA) sponsorship, which offer the possibilities of compact power sources, which could be advantageous. These turbine generators, if successful, could potentially have specific powers up to $1,000 \mathrm{~W} / \mathrm{kg}$ and specific energies to $3,500 \mathrm{Wh} / \mathrm{kg}$.

\subsubsection{Batteries}

A variety of battery options are currently commercially available. Table 3 and Fig. 2 summarize the specific power and specific energy for a number of available batteries.

The difficulty of meeting both the power and energy requirements while minimizing the weight is a concern with batteries. However, some recent developments could make the use of batteries more desirable for the exoskeleton application. First, AeroVironment, Inc., has recently tested $\mathrm{NiMH}$ batteries (both Energizer ${ }^{\mathrm{TM}}$ and Panasonic ${ }^{\mathrm{TM}}$ ) which have power densities of $1 \mathrm{~kW} / \mathrm{kg}$ for up to $10 \mathrm{~s}$ with a resulting drop in storage efficiency to only $2.8 \mathrm{Wh} / \mathrm{kg}$. Such a battery could be very useful for meeting peak loads in a hybrid system. Also, another company EVonyx has developed a zinc air power cell (sometimes referred to as a semi-fuel cell), that shows significant promise. The power cell utilizes a replaceable zinc fuel card that can be disposable or rechargeable. If the projected improvements in specific energy and specific power are met, the cell could meet both energy and power requirements at a reasonable weight and could be a viable potential power source for the exoskeleton application.

Table 3. Battery comparison.

\begin{tabular}{|l|c|c|c|}
\hline \multicolumn{1}{|c|}{ Type } & $\begin{array}{c}\text { Specific Energy } \\
(\mathrm{Wh} / \mathrm{kg})\end{array}$ & $\begin{array}{c}\text { Specific Power } \\
(\mathrm{W} / \mathrm{kg})\end{array}$ & Cycles to 80\% \\
\hline \hline Pb-acid & $30-45$ & 200 & $200-1000$ \\
\hline $\mathrm{Ni}-\mathrm{Cd}$ & $40-55$ & $190-260$ & $500-1000$ \\
\hline $\mathrm{NiMH}$ & $50-70$ & $180-200$ & $500-1000$ \\
\hline $\mathrm{Li}$ ion & $100-250$ & $300-800$ & $500-1200$ \\
\hline $\mathrm{Ag}-\mathrm{Zn}$ & $140-200$ & $100-330$ & $100-250$ \\
\hline $\mathrm{Ag}-\mathrm{Cd}$ & $55-95$ & $100-220$ & $300-500$ \\
\hline $\mathrm{Zn}-\mathrm{Air}$ & $150-300$ & $50-100$ & \\
\hline Al-Air & 350 & $500-600$ & \\
\hline
\end{tabular}




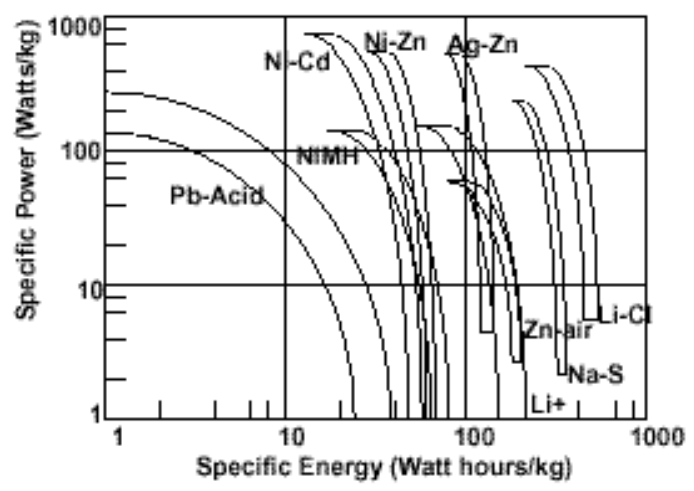

Fig. 2. Battery Ragone Diagram.

Source: Dowling, January 1997.

\subsubsection{Super Capacitors}

Super capacitors could also be used in a hybrid system to meet peak power demands. Figures 3 and 4 show the energy stored as well as the peak power available in super capacitors (data taken from Maxwell Technologies' Ultra Capacitor Series). From the figures, it can be seen that a relatively high specific power of $7 \mathrm{~kW} / \mathrm{kg}$ and a relatively low specific energy of $3.5 \mathrm{Wh} / \mathrm{kg}$ are available. Thus, the super capacitors can provide a significant amount of power over a short period of time and could be extremely useful for load leveling in hybrid systems.
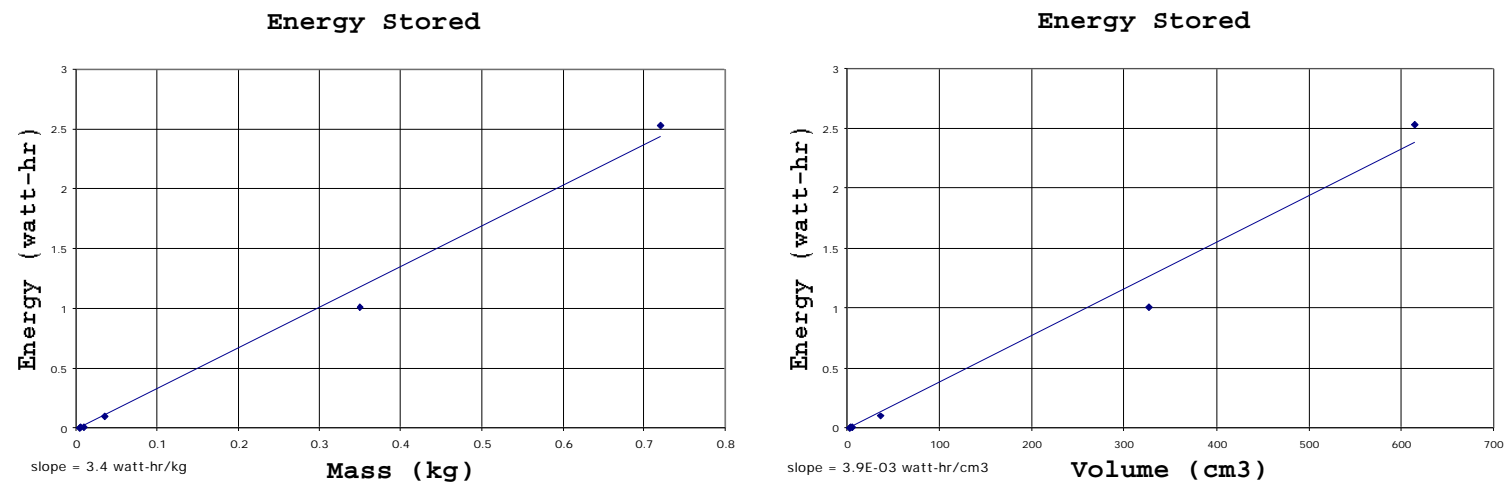

Fig. 3. Super capacitor energy storage vs mass and volume. 

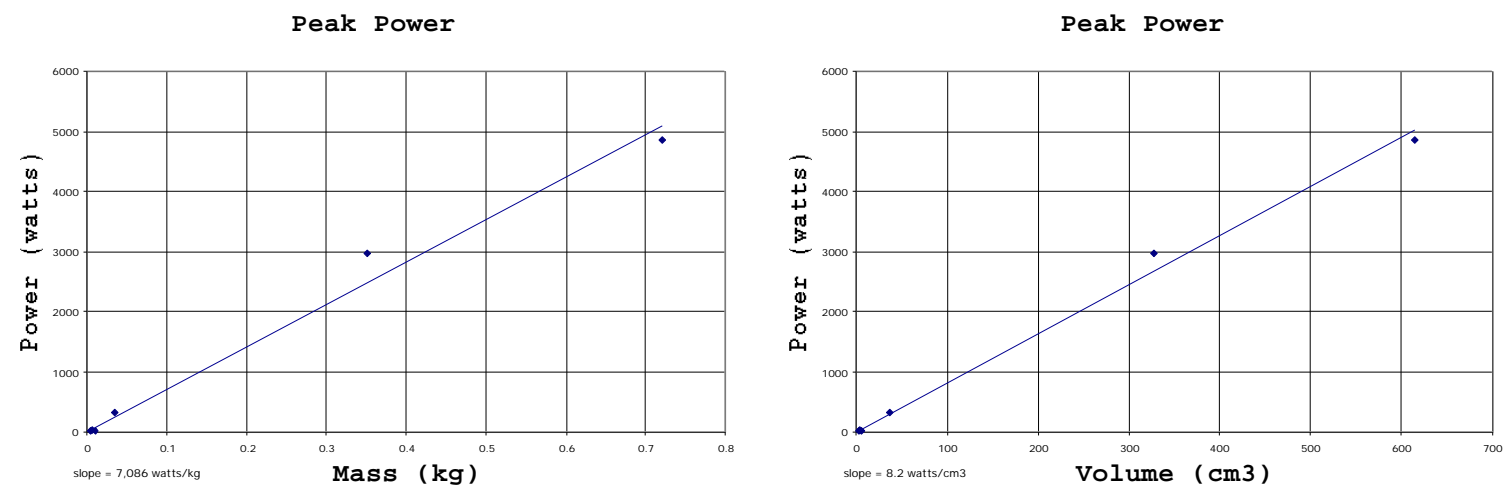

Fig. 4. Super capacitor peak power vs mass and volume.

\subsection{Power Sources Summary}

A power source for an exoskeleton must satisfy both power and energy requirements. With the significant variability in anticipated power demands, the ability of the power source to respond to peak loads without impeding performance is essential. Over-sizing a single power source to meet both power and energy requirements is not consistent with the need for efficiency required by this application. A hybrid power system, where transient peak power demands are met with one source and mission energy requirements are met with another source, can enhance efficiency at the expense of a more complicated system. Super capacitors and NiMH batteries are both capable of meeting peak transient load requirements, but they are insufficient as an energy source. A fuel cell fed by hydrogen, which is generated by a chemical reaction and an ICE both are capable of meeting system energy requirements.

Table 4 compares the weight for three possible power sources, diesel engine, fuel cell, and batteries, as well as four possible hybrid systems. While the weights for the ICE are lower than those for the fuel cell, it must be noted that the ICE weights do not include provisions for signature (noise, thermal, and emissions) reduction and vibration damping. These can be compensated for, but at the expense of increased complexity and weight.

Fuel cells allow for more stealthy operation because of their quiet operation, relatively low temperatures, and benign emissions (water). While there are development issues remaining to be solved for fuel cells, primarily regarding the hydrogen source, there appear to be viable options. These are currently being pursued by commercial suppliers and are likely to be readily available in the near future. Integrating a super capacitor or NiMH battery with a fuel cell fed by chemically generated hydrogen appears to be the most promising system, which can best meet the combination of power, energy, and signature objectives and safely function in close proximity to a human operator. 
Table 4. Power source comparison.

\begin{tabular}{|c|c|c|c|c|c|c|}
\hline Power Source Type & $\begin{array}{l}\text { Specific } \\
\text { Power } \\
(\mathrm{kW} / \mathrm{kg}) \\
\end{array}$ & $\begin{array}{c}\text { Specific } \\
\text { Energy } \\
(\mathrm{kWh} / \mathrm{kg})\end{array}$ & $\begin{array}{c}\text { Energy/ } \\
\mathrm{kg} \text { of Fuel } \\
(\mathrm{kWh} / \mathrm{kg})\end{array}$ & $\begin{array}{c}\text { Weight for } \\
\text { Power } \\
(\mathrm{kg})\end{array}$ & $\begin{array}{c}\text { Weight for } \\
\text { Energy } \\
(\mathrm{kg})\end{array}$ & $\begin{array}{c}\text { Total } \\
\text { Weight } \\
(\mathrm{kg}) \\
\end{array}$ \\
\hline$\overline{\overline{\text { Diesel ICE }}}$ & $\overline{0.4}$ & & $\overline{\overline{3.3}}$ & $\overline{5.0}$ & $\overline{c 1.4}$ & $\overline{c 6.4}$ \\
\hline PEM Fuel Celf.,3 & 0.225 & & 1.4 & 8.9 & 3.4 & 12.3 \\
\hline Li Ion Batteriest & 0.5 & 0.25 & & 4.0 & 19.2 & 19.2 \\
\hline $\begin{array}{l}\text { Hybrid } \\
\text { Fuel Cell } \\
\text { Battery } \\
\text { Total }\end{array}$ & $\begin{array}{c}0.225 \\
1.0\end{array}$ & & 1.4 & $\begin{array}{l}2.7 \\
2.0\end{array}$ & 3.4 & 8.1 \\
\hline $\begin{array}{l}\text { Hybrid } \\
\text { Fuel Celp } \\
\text { Super Capacitor } \\
\text { Total } \\
\end{array}$ & $\begin{array}{c}0.225 \\
7.0\end{array}$ & & 1.4 & $\begin{array}{l}2.7 \\
0.3\end{array}$ & 3.4 & 6.4 \\
\hline $\begin{array}{l}\text { Hybrid } \\
\text { Diesel ICE } \\
\text { Battery } \\
\text { Total }\end{array}$ & $\begin{array}{l}0.4 \\
1.0\end{array}$ & & 3.3 & $\begin{array}{l}1.5 \\
2.0\end{array}$ & 1.4 & 4.9 \\
\hline \begin{tabular}{l|} 
Hybrid \\
Diesel ICE \\
Super Capacitor \\
Total \\
\end{tabular} & $\begin{array}{l}0.4 \\
7.0\end{array}$ & & 3.3 & $\begin{array}{l}1.5 \\
0.3\end{array}$ & 1.4 & 3.2 \\
\hline $\begin{aligned} \text { Requirements: } & \text { Avg Power }(\mathrm{kW})= \\
& \text { Peak Power }(\mathrm{kW})= \\
& \text { Energy }(\mathrm{kWh})= \\
1 & \text { Based on specific ener } \\
2 & \text { Sized to meet peak pov } \\
3 & \text { Specific energy based } \\
4 & \text { Total weight based on } \\
5 & \text { Sized to meet average } \\
6 & \text { Sized to meet peak pow }\end{aligned}$ & $\begin{array}{l}0.6 \\
2.0 \\
4.8 \\
\text { gy or fuel cons } \\
\text { ver and energy } 1 \\
\text { on } 40.0 \mathrm{kWh} / \mathrm{k} \\
\text { energy requiren } \\
\text { power and eners } \\
\text { er requirements }\end{array}$ & $\begin{array}{l}\text { on. } \\
\text { ements, in } \\
\text { her heatin } \\
\text { uirements }\end{array}$ & $\begin{array}{l}\text { g fuel. } \\
\text { e) of } \mathrm{H}_{2} \text {. A }\end{array}$ & $7 \% \mathrm{H}_{2}$ by & $\%$ efficiency. & \\
\hline
\end{tabular}

\section{COMPARISON OF ACTUATORS}

The purpose of this section is to compare various types of actuator technologies subject to their relevance to the exoskeleton project. This section is not meant to be a primer about actuators but a comparison of potential relevant technologies. A designer must make decisions based on critical design parameters such as (1) power/mass, (2) power/volume, (3) stress, (4) strain, (5) steady-state efficiency, (6) power expended during load holding, (7) bandwidth or tracking performance, (8) auxiliary transmission system, (9) auxiliary power modulation equipment, and (10) ease of controllability. Depending on the type of actuator, some of the critical design parameters will not be applicable or not available due to design specificity. Actuator technologies will be broken down into two major groups: conventional and non-conventional. Conventional actuators are electric motors, hydraulic, and pneumatic. The non-conventional actuators are the piezoelectric and magnetorestrictive. There will be a brief discussion of the shape memory alloy and polymers. While others have examined these types of actuators in the past, their relevance to the exoskeleton project will be the main focus on this section. Before comparisons can be made, a brief description of the demands that will be imposed on the actuators of an exoskeleton will be given. 


\subsection{Exoskeleton Actuator Demands}

To understand the magnitude of torques and power required for exoskeleton actuators, loads for a human will be scaled to account for the higher weight of a loaded exoskeleton system. The loads are based on the assumption of a $150 \mathrm{lb}$ individual with a $150 \mathrm{lb}$ load to represent a $300 \mathrm{lb}$ exoskeleton system (exoskeleton plus load). Only two joints, the hip and knee joints, will be considered to understand the load and power required for an exoskeleton actuator. Studies at Oak Ridge National Laboratory (ORNL), which looked at a variety of poses, showed a kneeling pose yielded the largest loads of 1,350 in.-lb $(153 \mathrm{~N}-\mathrm{m})$ for hip joint and $6300 \mathrm{in} .-\mathrm{lb}(712 \mathrm{~N}-\mathrm{m})$ for knee joint. Examination of a simple knee-bend-type of movement, where the human and load are moving vertically up and down with respect to gravity with $17.5 \mathrm{in}$. of motion in $1 \mathrm{~s}$, shows power levels for the knee joint can approach $600 \mathrm{~W}$ and for the hip joint around 120 W. Peak knee-joint velocities can approach almost $200 \% \mathrm{~s}$ and for the hip peak velocities around $100 \%$ are possible. For walking and running, peak joint velocities can go up by actor of three times these numbers.

Based on human-motion profiles for simple ballistic-type of walking (McMahon, 1984), a periodic gait pattern of around $2 \mathrm{~Hz}$ can easily be seen, and even higher numbers are possible for other types of motions (e.g., running). Power requirements for simple ballistic walking will be significantly lower than for a deep-knee-bend-type of movement; however, the actuator would have to be rated for the worst case scenario.

To evaluate different types of actuators, actuators around the 500- to $1000-\mathrm{W}$ levels will be discussed with thousands of in.-lb of torque capability and with the closed-loop bandwidth to accurately track a $2 \mathrm{~Hz}$ gait.

\subsection{Conventional Actuators}

Conventional actuators are those that are common for robotic manipulators. Basically, there are three major types: electromagnetic (electric motors), pneumatic, and hydraulic. For the electromagnetic category, only brushless dc motors will be examined since they are the closest match to the intent of this project. Reluctance-based motors such as those from NSK Nippon Seiko called Motornetics Megatorque ${ }^{\mathrm{TM}}$ motors will not be examined because, while they have a somewhat higher torque to mass ratio than do standard brushless dc motors, their overall larger diameters and associated power electronics puts them at a disadvantage pertaining to packaging. Pneumatic and hydraulic actuators based on classical servovalve control will be examined and will be compared to each other.

\subsubsection{Electromagnetic Actuators (Brushless Motors)}

About 50 motors from Inland Motors, Inc., were examined. All were high-end frameless, brushless motors. A plot of the continuous power versus mass is shown in Fig. 5. For electric motors (specifically those around 0.5 to $1 \mathrm{~kW}$ level) the power-to-mass ratio can be bounded by a line, which has a slope of roughly $500 \mathrm{~W} / \mathrm{kg}$. The continuous torque out of an electric motor per unit total motor volume is shown in Fig. 6. 


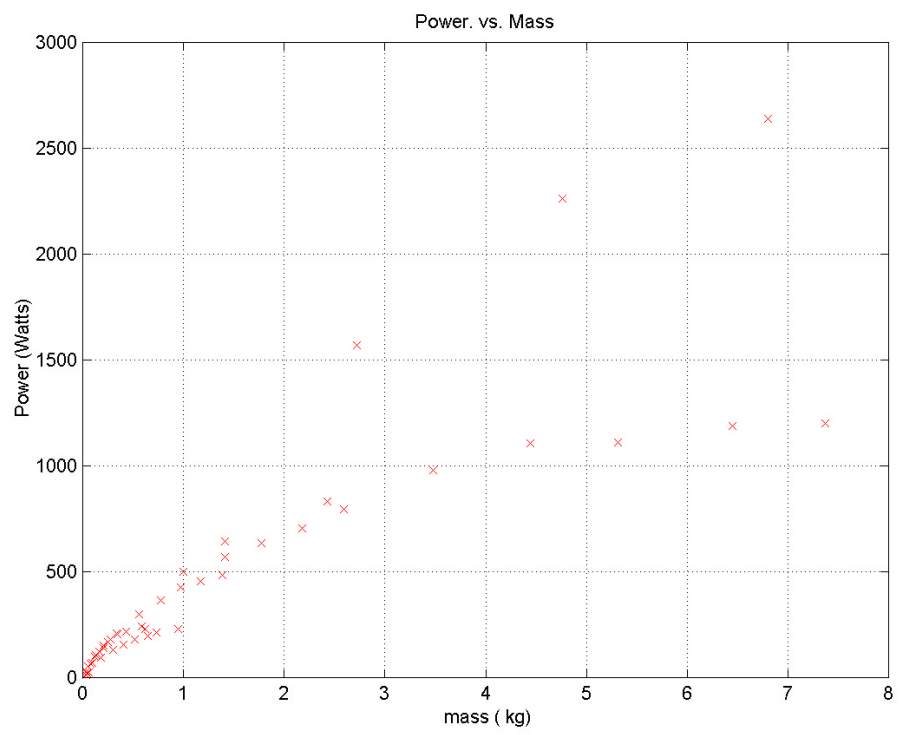

Fig. 5. Power vs mass for frameless brushless dc motors.

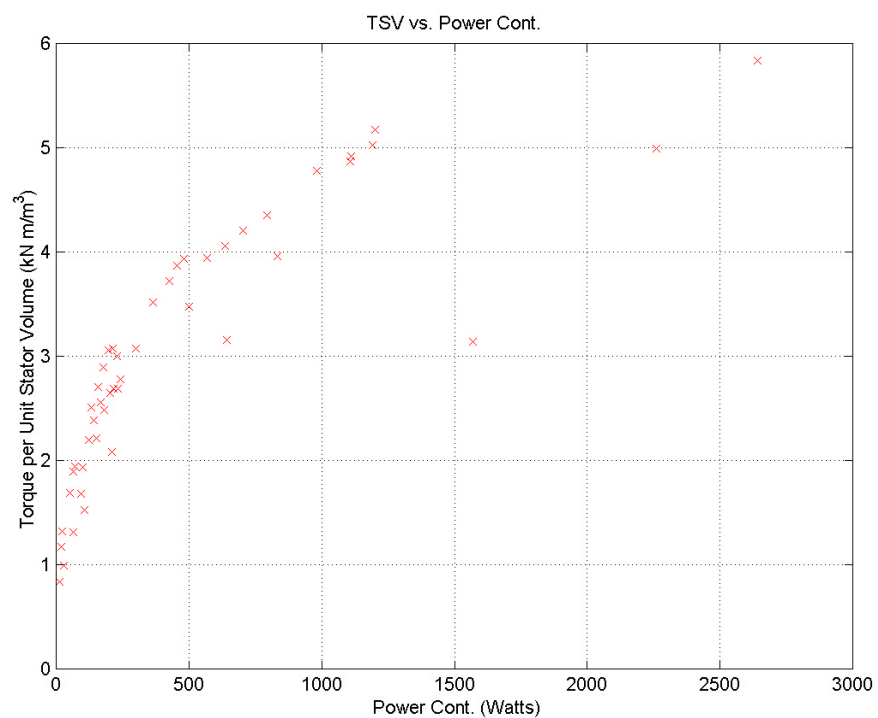

Fig. 6. Torque per unit motor volume vs continuous power.

For 500- to 1000-W motors, the continuous torque per unit motor volume varies from 4 to $5 \mathrm{KN} / \mathrm{m}^{3}$. Figure 7 shows the continuous torque per mass for the same power range, which is under $3 \mathrm{Nm} / \mathrm{kg}$. The continuous torque per unit volume and continuous torque per unit mass ratios will increase if the thermal operating range of the motors can be exceeded (e.g., air cooling, special higher temperature rated wires, etc.). Some researchers cite numbers twice as high as the ones given (Hollerbach, 1992), which can be obtained by the so-called megatorque motors, which are manufactured by NSK; however, as previously mentioned, the package volume of these motors are probably unsuitable for an exoskeleton. 


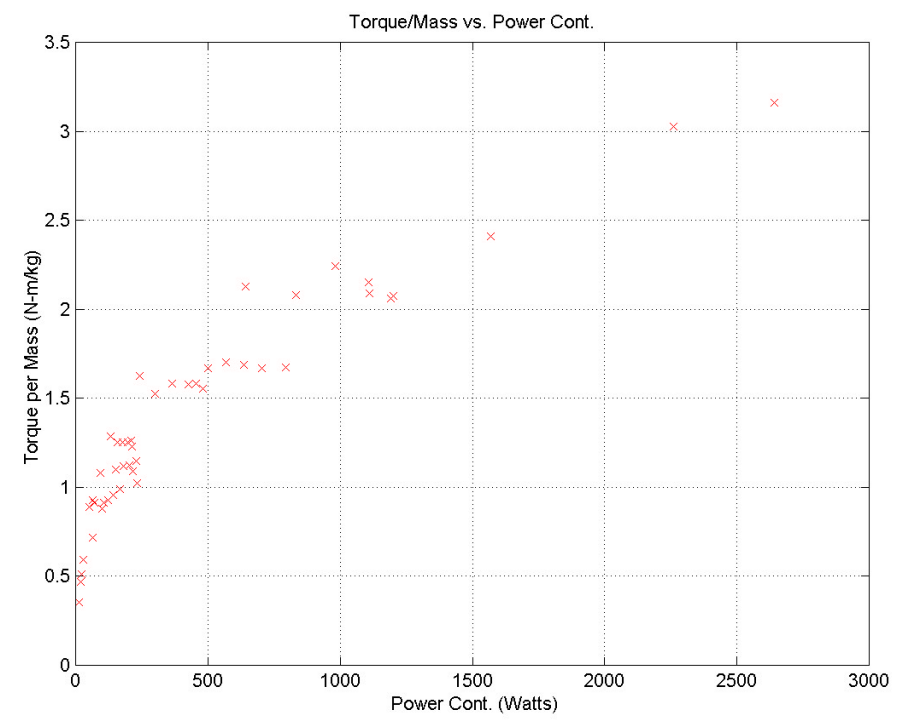

Fig. 7. Torque per mass vs power continuous.

Upper values for the shear stress over the rotor surface of an electric motor have been reported to be under 5 psi (higher values are possible if a cooling system is added). These low values of shear stress are not subject to significant improvements and are currently limited by heat transfer and the magnetic saturation limits of supporting ferrous structure (Miller, 1989). Steady-state electromechanical efficiency is around 85 to $95 \%$. The power required for holding rated torque at stalled conditions can range from 5 to $10 \%$ of the power rating of the motor. Basically, this means that while no mechanical power is being expended, significant power is required to merely hold the load. Mechanical brakes are typically not an option for a high-performance servo system.

Based on the $600 \mathrm{~W}$ required for the knee-joint actuator and the $120 \mathrm{~W}$ for the hip joint, and using a $500 \mathrm{~W} / \mathrm{kg}$ value for actuator mass sizing, a $1.2 \mathrm{~kg}$ actuator for the knee and $0.24 \mathrm{~kg}$ actuator for the hip would be required. The equivalent torque rating for these actuators, based on the $3 \mathrm{Nm} / \mathrm{kg}$ torque sizing value, would be $3.6 \mathrm{~N}-\mathrm{m}$ for the knee joint actuator and $0.72 \mathrm{~N}-\mathrm{m}$ for the hip joint actuator. Since we need a $712 \mathrm{~N}-\mathrm{m}$ for the knee joint, a transmission system (e.g., gearbox) with about a 200:1 ratio is needed for the knee joint. Likewise, for the hip joint we need $153 \mathrm{~N}-\mathrm{m}$, and a transmission system again of about a 200:1 ratio will be required. Steady-state transmission efficiencies are typically 80 to $90 \%$, which means that the motors would have to be 10 to $20 \%$ larger from a power perspective. Depending on the type of transmission system, such as a harmonic to a planetary type of gearhead, the transmission system can increase the overall package volume by $20-50 \%$. For simplicity, the impact of the actuators and transmission system on the overall weight of the exoskeleton, while not insignificant, has been ignored in terms of the joint velocity. 


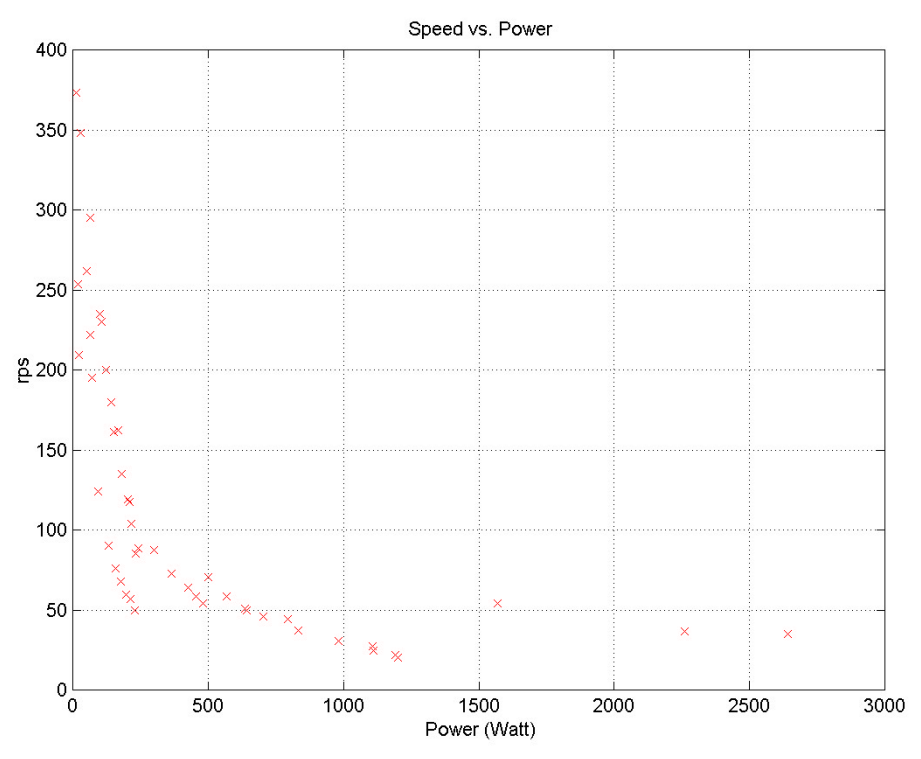

Fig. 8. Speed (revolutions/s) vs continuous power.

From Fig. 8, we see that the maximum unloaded speed of an electric motor is under 75 revolutions/s. When divided by the 200:1 gear ratio, the maximum unloaded angular velocity is $123 \%$. Since running will require significantly higher peak joint velocities, a significantly larger motor size will be required by roughly a factor of 2 (i.e., the power density will decrease by a factor of 2) to achieve adequate joint velocities. In summary, a transmission system is needed for an electric system, and it can significantly impact the overall package volume and efficiency. To track peak joint velocities, the motor size will have to be increased significantly because of the high gear ratios required.

The volume and mass of the power electronics associated with an electric motor vary greatly depending on the power source (i.e., dc or ac) and how close the voltage of the supply is to the voltage needed by the motor etc. Typically, on industrial robotic manipulator systems (where weight is not a major concern), the power electronics can easily exceed the weight and volume of all the actuators. Power-to-volume densities are typically in the 2- to 40-W/in ${ }^{3}$ range (as compared to around $25 \mathrm{~W} / \mathrm{in}^{3}$ for electric motors). By judicial design, the volume and mass of the associated power electronics can be significantly reduced, but not without a significant design effort.

\subsubsection{Hydraulic Actuators}

Hydraulic actuators are fundamentally different than electric motors in that the amount of flow into a hydraulic actuator is limited by the maximum amount of flow possible from the pumping source and any flow restrictions caused by flow control elements such as servo valves. Thermal limitations associated with electric motors do not apply to hydraulic actuators since the hydraulic fluid cools and lubricates the system. Material restrictions are based only on pressure limits. As a rule of thumb, the power to mass ratio is about five times that of an electric motor and the power to volume ratio is about ten times that of an electric motor for many applications. Again, 
these numbers could be higher or lower depending on the particular application. The pressure levels are from 3,000 to 5,000 psi (or 21 to $35 \mathrm{MPa}$ ), with 3,000 psi being an industrial standard. Maximum strain levels correspond to the stroke length over the total actuator length, which can range from 0.5 to 0.8 for most actuators. For rotary actuators, the maximum strain levels do not apply. Unlike the electric motor, the force or torque that can be produced can be easily matched to the application simply by changing the effective area for a linear actuator or the effective displacement for a rotary actuator. Therefore, a transmission system is typically not required. Only the friction at the seals and leakage affects limit the steady-state mechanical efficiency. For linear actuators, high, steady-state mechanical efficiencies are possible and are in the upper $90 \%$ range. Rotary actuators range from 80 to $90 \%$. For load-holding applications, zero power is expended for linear actuators with asymmetrical cylinders and a small amount of power is expended in the 1 to $10 \%$ range because of leakage for symmetrical cylinders and rotary actuators.

The bandwidth of a hydraulic actuator can be derived based on a few simplifying assumptions; (1) only a symmetrical cylinder design will be assumed; (2) fluid volume outside of the cylinder will be ignored; and (3) half of the system pressure is used to hold the load against gravity. In addition, the fluid bulk modulus will be assumed to be at 100,000 psi (or $689 \mathrm{MPa}$ ) and the system pressure is set at $3000 \mathrm{psi}(21 \mathrm{MPa})$. Starting with the natural frequency, $\mathrm{f}_{\mathrm{o}}(\mathrm{in} \mathrm{Hz})$, the derivation of a hydraulic cylinder is (Viersma, 1980)

$$
f_{o} \geq \frac{1}{\pi} \sqrt{\frac{A \beta}{M S}}=\frac{1}{\pi} \sqrt{\frac{A \beta g}{M g S}}
$$

or

$$
f_{o} \geq \frac{1}{\pi} \sqrt{\frac{\beta g}{\frac{M g}{A} S}}=\frac{\sqrt{2}}{\pi} \sqrt{\frac{\beta g}{P_{s} S}}
$$

which can be further simplified to

$$
f_{o} \sqrt{S} \geq \frac{\sqrt{2}}{\pi} \sqrt{\frac{\beta g}{P_{s}}}=8.1
$$

where

$$
\begin{aligned}
& \mathrm{M}=\text { load mass }(\mathrm{kg}) \\
& \mathrm{A}=\text { effective stroke area }\left(\mathrm{m}^{2}\right) \\
& \mathrm{P}_{\mathrm{s}}=\text { supply pressure }(3000 \mathrm{psi}) \\
& \mathrm{S}=\text { stroke length }(\mathrm{m}) \\
& \mathrm{g}=\text { gravity constant }=9.807 \mathrm{~m} / \mathrm{s}^{2}, \text { and } \\
& \beta=\text { fluid bulk modulus constant }(100,000 \mathrm{psi})
\end{aligned}
$$


As an example for a stroke length of 6 in. $(0.1524 \mathrm{~m})$, the natural frequency would be above $21 \mathrm{~Hz}$. Depending on the type of controller (i.e., position or pressure acceleration and type of feedback), the closed-loop bandwidth could be as low as 0.15 [for positional feedback, (Merritt, 1967)] to 0.5 [for acceleration feedback, (Viersma, 1980)] of the natural frequency value with 0.15 typical for industrial applications. For this example, the closed-loop bandwidth would typically be greater than $3 \mathrm{~Hz}$.

Control of a hydraulic actuator for high-precision applications is typically through a servo valve. The bandwidth for most high performance servo valves that would be applicable to the exoskeleton project would be typically from 50 to $100 \mathrm{~Hz}$ (see Moog's model 30 valves at www.moog.com). Losses associated with a servo valve could be as high as about 1/3 of the maximum power to the hydraulic actuator since most servo valves are rated for a 1,000-psi drop across their orifices. Reliability of a hydraulic actuator is mainly limited by seal and/or gland wear and impact loads. Servo valves associated with a hydraulic actuator are more likely to fail. However, with suitable control of the overall filtration levels of hydraulic fluid, servo valves can have a long service life (exceeding over one quarter million hours mean time before failure for valves such as the deflector jet type) as noted by their application in the commercial aircraft industry.

The power electronics associated with the hydraulic servo valve and actuator can be inconsequential. For a two-stage servo valve, the drive current for the torque motor is typically well within the linear operational amplifier range (e.g., the Moog's model 30 is typically rated around $16 \mathrm{~mA}$ ). This again adds to the advantage of hydraulic actuators as compared to electric motor actuators.

One final point associated with hydraulic servo systems which needs to be mentioned, is the noise problem associated with the pumping system. Hydraulic pumps are typically noisy at fairly low frequency, thus making sound proofing at reasonable packaging volumes difficult because of the large acoustical wavelengths.

\subsubsection{Pneumatic Actuators}

Pneumatic actuators are very similar to the hydraulic actuators in many respects. However, a few exceptions are especially noteworthy. Air is typically a poor lubricating and cooling medium, as compared to a hydraulic fluid medium. Losses are higher because of fluid leakage through seals. Furthermore, air is significantly more compressible than a hydraulic fluid medium. Compressibility of air will significantly lower the natural frequency of a pneumatic control system. Significant energy can be stored in this medium, which can be used to one's advantage, such as mitigating impact loads, or it can be a safety problem because of the possible burst hazard it presents. In comparison, hydraulic fluid has no significant energy storage capability. Also, as a practical limitation, the supply pressure for a pneumatic storage device is limited to 100 to $150 \mathrm{psi}$ as compared to 3,000 to 5,000 psi, for a hydraulic system. Power to weight and power to volume for pneumatics can vary depending on the type and application. For elastic-type pneumatic actuators, such as the McKibben muscle (Chou, 1996), these ratios can rival hydraulic actuators. For hard-shell-type pneumatic actuators, these ratios are closer to 
electric actuators; however, the pneumatic actuators are only limited by the mass flow from the pump and any flow restrictors such as a servo valve.

While at first glance pneumatic actuators hold many advantages such as (1) high power to weight and power to volume (for elastic type pneumatic actuators), (2) good impact load mitigation, and (3) energy storage capability; there are some important limitations. While losses are typically higher than hydraulic and safety is always a concern, the main barrier for pneumatic types of actuators is the bandwidth caused by the compressibility of the air. Based on similar assumptions made for a hydraulic actuator and starting with the basic natural frequency formulation of a pneumatic cylinder (Andersen, 1967)

$$
f_{o} \geq \frac{1}{\pi} \sqrt{\frac{k_{p}}{M}}=\frac{1}{\pi} \sqrt{\frac{4 n P_{s} A_{p}^{2} g}{M g V_{t}}}
$$

or

$$
f_{o} \geq \frac{1}{\pi} \sqrt{\frac{n P_{s} g}{\frac{M g}{A_{p}} \frac{V_{t}}{A_{p}}}}=\frac{1}{\pi} \sqrt{\frac{n g}{S \frac{M g}{A_{p}} / P_{s}}}=\frac{\sqrt{2}}{\pi} \sqrt{\frac{n g}{S}}
$$

which can be further simplified to

$$
f_{o} \sqrt{S} \geq \frac{\sqrt{2}}{\pi} \sqrt{n g}=1.4 \text { to } 1.7
$$

where

$\mathrm{n}=$ polytropic exponent which can vary from 1 to 1.4 (ratios of specific heat for air),

$\mathrm{k}_{\mathrm{p}}=$ effective stiffness of gas in cylinder, and

$\mathrm{A}_{\mathrm{p}}=$ effective area of pneumatic cylinder.

Comparison of the natural frequency of hydraulic and pneumatic actuators by means of Eqs. (4) and (5), clearly shows that for a given stroke length the natural frequency of hydraulics is 5 to 6 times higher than pneumatic actuators. Regardless of the type of feedback scheme, since whatever can be applied to a pneumatic servo can be applied to a hydraulic servo, the closedloop bandwidth of a hydraulic system will be 5 to 6 times higher than a pneumatic servo-system for the same stroke length. For the example in the previous section, the hydraulic closed-loop bandwidth was calculated to be greater than $3 \mathrm{~Hz}$, while for pneumatics, it would be anticipated to be greater than $0.5 \mathrm{~Hz}$. Closed loop tracking at $2 \mathrm{~Hz}$, for this example, can only be achieved with hydraulic actuators. 


\subsection{Non-Conventional Actuators}

Non-conventional actuators are those that are typically described as associated with smart materials, such as piezoelectric, magnetostrictive, shaped memory alloys, and electroactive polymers. While there are others (such as those associated with magnetorheological and electrorheological fluids, and electrostrictive materials), only a few of these materials are seriously being considered as viable candidate for the exoskeleton project. In the future and after more research, these other candidates could play an important role in actuator applications.

\subsubsection{Piezoelectric Actuators}

Large forces and small displacements occur in a piezoelectric crystal when an electric field is applied. Compressive stress levels can be as high as $35 \mathrm{MPa}$ (5,000 psi), whereas the tensile stress levels can be only 5 to $10 \%$ of the compressive stress level. Typically, a mechanical force bias is required to avoid the tensile stress limits. Displacements are typically very small for piezoelectric materials. Currently, PZT ceramics are the materials of choice for piezoelectric ceramic actuators. These materials have piezoelectric coefficients $\mathrm{d}_{33}$, around 200 to $750 \mathrm{pC} / \mathrm{N}$, and strain levels from 0.05 to $0.1 \%$. However, there is a new piezoelectric material that has the potential to change future piezoelectric actuators. This new material, a single crystal form of relaxor-based ferroelectric materials (PZN-PT), has been observed to have piezoelectric coefficients $\mathrm{d}_{33}$, around $2,000 \mathrm{pC} / \mathrm{N}$, and strain levels from $0.5 \%$ to $1.0 \%$. While these materials have been known for several years, their potential for high performance actuators has recently been recognized (Park, 1997). Applications that require high forces and small displacements, such as those in acoustic applications are immediate application areas. However, ferroelectric crystals experience a hysteresis effect, which make them difficult to control for high-precision applications.

One difficulty of using piezoelectric material pertains to converting small displacements to large motion (i.e., the transmission problem). Various ideas include the "inch-worm", where microstepping action through rapid lock-and-move sort of motion are used to create a large linear motion. Another concept is that of a piezoelectric hydraulic pump (Nasser, 2000), where small quantities of fluid moves at very high frequencies. The accumulation of small drops of fluid at a high rate adds up to a large flow rate. Both of these concepts are based on the idea of the cyclic motion of the piezoelectric material. A simplified electromechanical model is shown in Fig. 9. The left-side ports are the electrical ports where a voltage is applied and current is injected into the crystal. The right-side port is where force represents the equivalent voltage and velocity represents the current. A mechanical load, $Z_{\mathrm{m}}$, is shown attached to the mechanical port. 


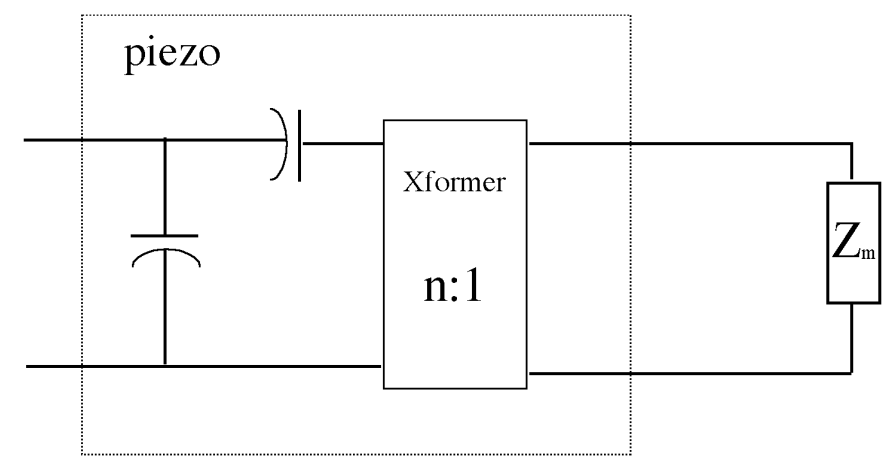

Fig. 9. Electromechanical model of piezoelectric actuator with mechanical load.

If the mechanical load can be represented as a purely resistive load that has been optimized to achieve maximum power transfer at a given frequency, $\omega$, then it can be shown that the power per volume of the piezoelectric actuator can be approximated to

$$
\frac{\text { power }}{\text { volume }}=\left(\frac{1}{2} \varepsilon{ }_{33}^{T} E^{2}\right) k^{2} \omega
$$

where

$\mathrm{E}=$ electric field, typically under $10^{6} \mathrm{~V} / \mathrm{m}$,

$\varepsilon_{33}=$ electric permittivity, and

$\mathrm{k}^{2}=$ electrical to mechanical conversion constant $(0.75$ for $\mathrm{PZN})$.

The term in parenthesis is the electrical energy density stored in the piezoelectric material, and for modest electric fields, this term could have values of $0.02 \mathrm{~J} / \mathrm{cm}^{3}$ (or $2.7 \mathrm{~J} / \mathrm{kg}$ for a typical density value of $8,200 \mathrm{~kg} / \mathrm{m}^{3}$ ) for the single-crystal piezoelectric material PZN. Larger energystorage terms have been reported in the literature, but because of fatigue life limitations (remember that because of the transmission problem, billions of cycles will be required from this material), this reduced value is more reasonable. To obtain over $2,500 \mathrm{~W} / \mathrm{kg}$ (which is a factor of 5 times that of an electric motor and would therefore rival that of hydraulic), the cyclic frequency would have to be over $200 \mathrm{~Hz}$. Because of the nonlinear nature of the load expected for the "inch worm" or the piezoelectric pump, a much higher frequency (maybe around $1 \mathrm{kHz}$ ) would be required. The steady-state efficiency of running the actuator around $1 \mathrm{kHz}$ would be approximately $85 \%$. The load-holding capacity of the piezoelectric material is excellent-no power is wasted.

The final major challenge associated with piezoelectric actuator is the associated power electronics to control it. Typical piezoelectric actuators are driven by high-voltage power sources of around 400 to $1,000 \mathrm{~V}$. The size of the drive electronics frequently exceeds the overall packaging volume of the actuator by one order of magnitude if not larger. The basic problem of power transfer can be seen in Fig. 9. How one can transmit charge readily to the mechanical load without wasting the energy stored in the two capacitors is the salient design problem and is still under research (Newton, 1996). 


\subsubsection{Magnetostrictive Actuators}

Magnetostrictive actuators are very similar to piezoelectric actuators. Applying a magnetic field creates high forces and small displacements. The magnetic domains in the material rotate causing significant dimensional change in the material. Currently, Terfenol-D is the magnetostrictive material in common use. Large strains are typically reported, but in practice values under $0.2 \%$ are commonly observed. Stress values, while reported to be higher than piezoelectric materials, are commonly below commercial PZT values when a direct comparison is done (see www.etrema-usa.com for Terfenol-D actuators and www.physikinstrumente.com/pztactuators for the PZT actuators). All of the issues associated with piezoelectric actuators also apply to magnetostrictive actuators. The simplified electromechanical model of the magnetostrictive actuator is shown in Fig. 10, where the left port is the electrical port with current and voltages as inputs and the output port is the mechanical port with velocity and force. The load-holding capability of the material is limited by the $\mathrm{i}^{2} \mathrm{R}$ losses associated with generating a magnetic field and is similar to electric motors with a range of 4 to $8 \%$ of the continuous power rating for maximum load. Overall efficiency numbers are hard to obtain, but due to the highly nonlinear nature of the hysteresis of the magnetic material and the $i^{2} R$ losses associated with the electrical coils, efficiencies should be less than those for PZT materials.

The issues associated with the power electronics also apply to the magnetostrictive materials. The basic problem of power transfer can be seen in Fig. 10. How one can transmit current readily to the mechanical load without wasting the energy stored in the two inductors is the salient design problem and is still under research (Kellogg, 1996).

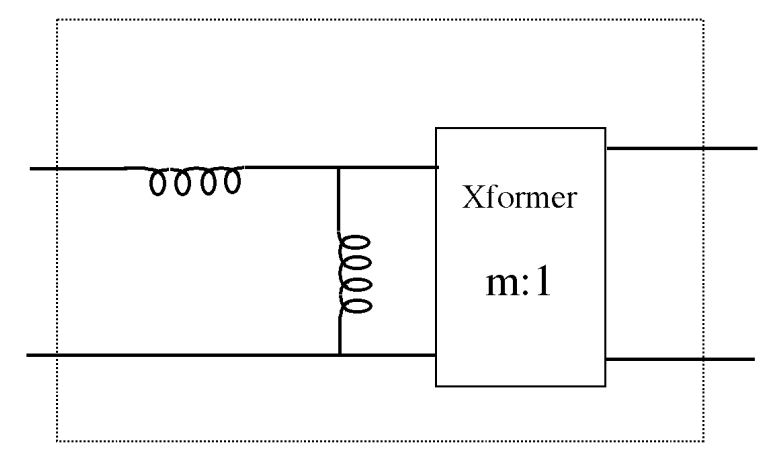

Fig. 10. Magnetostrictive electromechanical model.

\subsubsection{Shaped Memory Alloy (SMA) and Electroactive Polymers (EAP)}

SMAs (NiTi), while having impressive compressive stresses of $200 \mathrm{MPa}$ (i.e., they can pull but not push), have overall energy efficiencies under 3\%. Without large amounts of cooling, overall bandwidth will be below $1 \mathrm{~Hz}$. SMA are not serious contenders for the exoskeleton application unless the overall efficiencies and bandwidth issues can be seriously extended. 
EAPs are an exciting new material that has many anthropomorphic characteristics similar to muscle. In the majority of EAP actuators, the actuation mechanism is based on ionic species movement in a polymer network (Wax, 1999). EAP actuators can be characterized as gels; ionic polymer metal composites; perfluorinated, ion-exchanged, membrane platinum; or conductive polymers. EAP actuators hold tremendous potential especially for microactuation applications. For macroactuation applications, such as for the exoskeleton project, speed of response (i.e., bandwidth) and higher levels of electrical-to-mechanical power conversion ratios are needed. Currently, macro EAP actuators fall well below electric motor power and force (or torque) densities (Wax, 1999).

\subsection{Actuator Recommendation}

Of the conventional actuators (Table 5), it appears that hydraulics is the best candidate for an exoskeleton application. The power-to-weight and power-to-volume ratios of hydraulics typically exceed the ratios for electromagnetic actuation by factors of 10 and 5 respectively. The closed-loop bandwidth of pneumatics is typically 5 to 6 times less than that for hydraulics, thus limiting the ability to track at $2 \mathrm{~Hz}$. Based on packaging and the ability to track the human, hydraulics is the preferred conventional actuator.

Table 5. Comparison of conventional actuators.

\begin{tabular}{|c|c|c|c|}
\hline Item & Electromagnetic Actuators & Hydraulic Actuators & Pneumatic Actuators \\
\hline Bandwidth & $\begin{array}{l}\text { Transmission required. Motors } \\
\text { sized } 10 \text { to } 20 \% \text { larger due to } \\
\text { transmission efficiencies. }\end{array}$ & $\begin{array}{l}\text { High performance servos in the } \\
50 \text { to } 100 \mathrm{~Hz} \text { range. Dependent } \\
\text { on actuator and controller } \\
\text { design. }\end{array}$ & 5 to $6 \mathrm{x}$ less than hydraulics. \\
\hline $\begin{array}{l}\text { Power to } \\
\text { Weight }\end{array}$ & $\begin{array}{l}\text { Approximately } 1 / 10 \text { hydraulics } \\
\text { ratio. }\end{array}$ & Excellent. & $\begin{array}{l}\text { Elastic type actuators are } \\
\text { similar to hydraulics. Hard- } \\
\text { shell type actuators are similar } \\
\text { to electric actuators. } \\
\end{array}$ \\
\hline $\begin{array}{l}\text { Power to } \\
\text { Volume }\end{array}$ & $\begin{array}{l}\text { Approximately } 1 / 5 \text { hydraulics } \\
\text { ratio. }\end{array}$ & Excellent. & $\begin{array}{l}\text { Elastic type actuators are } \\
\text { similar to hydraulics. Hard- } \\
\text { shell type actuators are similar } \\
\text { to electric actuators. }\end{array}$ \\
\hline Packaging & $\begin{array}{l}\text { Transmission increases vol by } \\
20-50 \% \text {. Power electronics can } \\
\text { exceed size of actuator. }\end{array}$ & $\begin{array}{l}\text { No transmission. Power } \\
\text { electronics are inconsequential. } \\
\text { Sound proofing pumps } \\
\text { difficult. }\end{array}$ & Similar to hydraulics. \\
\hline $\begin{array}{l}\text { Load } \\
\text { Holding }\end{array}$ & $5-10 \%$ or rated power required. & $\begin{array}{l}\text { No power for linear actuators } \\
\text { with asymetrical cylinders. } 1 \text { to } \\
10 \% \text { for symetrical cylinders } \\
\text { and rotary actuators. }\end{array}$ & Similar to hydraulics. \\
\hline
\end{tabular}

However, there are issues concerning the use of hydraulics, which must be taken into account. First, the power loss at the servo valves associated with flow control is significant and has a serious impact on the overall power supply sizing. Second, noise is a serious problem associated with hydraulics that can be difficult to mitigate due to the large acoustical wavelengths. 
While none of the non-conventional materials have reached the level of maturity achieved with hydraulics, both the piezoelectric and the magnetostrictive materials hold great promise and should be investigated further. In particular, a piezoelectric pump was shown to have the potential for power densities approaching those of hydraulics, as well as high steady-state efficiency, and no wasted power holding a load. The magnetostrictive actuators are similar to piezoelectric actuators, but with lower anticipated efficiencies and load holding capability similar to that of electric motors. Power electronics is an issue for both that is the subject of on-going research.

\section{FUNDAMENTAL CONTROLS OBJECTIVES AND TOPOLOGY}

While biped control for autonomous robots is still an active research area, its application to an exoskeleton is almost negligible because the balancing capability of the human operator can be transferred to the exoskeleton. The transfer of balancing capability from the operator to the exoskeleton is based on bilateral force reflection. Historically, the major application of bilateral force reflection controls has been for teleoperator (master-slave) systems. There are three general types of control strategies used in a teleoperator system: (1) position-position, (2) position-force, and (3) force-force control. The first control strategy, which was used on the Hardiman, position-position control, refers to the type of sensory information (in this case positional information) being used in the "outer" feedback loop of both the master and slave. Position-position control is commonly implemented in most teleoperator systems. Two teleoperators ORNL built in the 1980s, the M2 and the Advanced Servo Manipulators, are examples of this type of control strategy that is common for systems that have kinematically similar master-slave manipulators. For kinematically dissimilar master-slave systems, positionforce control is commonly used. For human amplifier (or extender) type systems, where the master and slave are one integral unit such that the human operator and the manipulator are attached to a common point and bilateral force reflection is the primary performance objective, force-force control is commonly used.

The purpose of this section is to define the fundamental control objectives and outline the basic control topology associated with the design of any mechanical exoskeleton system. Issues, such as the amount of mass felt by the human operator, minimum feedback gains, determining the critical sensory feedback signals, and reflection of disturbance forces back to the operator will be discussed.

To avoid undue complexity, a simple 1-degree of freedom (DOF) system, shown in Fig. 11, will be examined to better understand the salient issues. Figure 11 shows two types of actuators: the first is the human actuator in parallel with the mechanical actuator (such as a hydraulic cylinder). Force sensing is represented by the oval symbols, and force sensing at the human and the mechanical actuator are shown. It should be mentioned that force sensing at the foot instead of at the mechanical actuator is also possible and would be preferred, but for the sake of simplicity, the sensing also shown in Fig. 11, will be useful for discussion. The mass of the human is represented by $M_{h}$, the exoskeleton mass is represented by $M_{e x}$, and the payload mass is represented by $\mathrm{M}_{\mathrm{p}}$. 
Three states will be considered in the analysis. The first is when the (mechanical) foot is on the ground with the exoskeleton system at rest. The second is when the (mechanical) foot first impacts the ground and the last when the 1-DOF system is off the ground. Linear analysis (in particular Laplace Transform theory with the s operator) will be assumed to adequately describe the basic physics for a fundamental understanding of a mechanical exoskeleton system. For state 1 , where the exoskeleton system is in contact with the ground and initially at rest (i.e., impact is ignored and the initial velocity is zero), the governing dynamic equations of the overall mechanical system can be described as

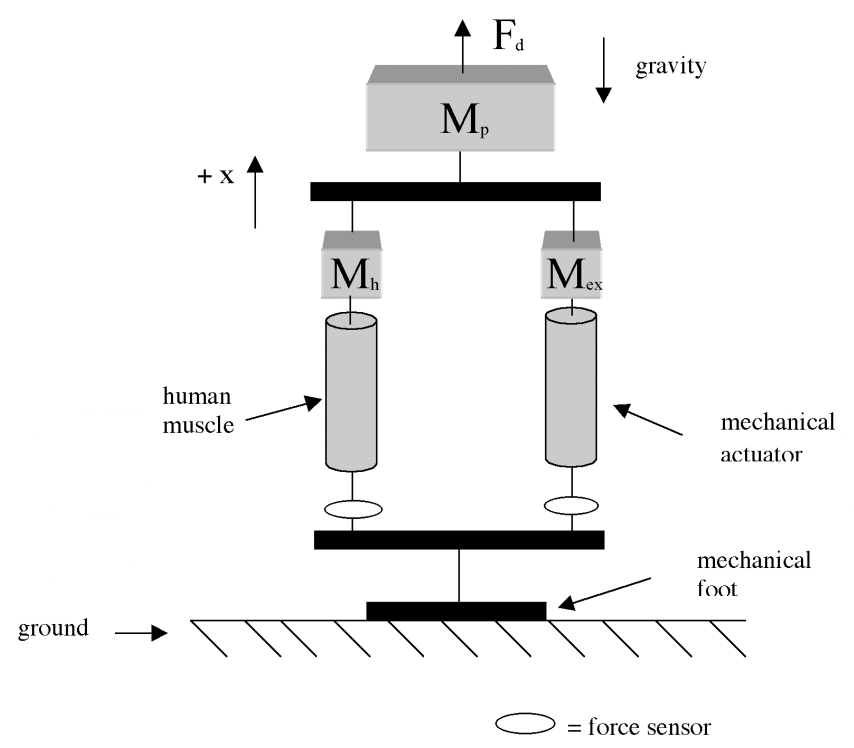

Fig. 11. One DOF exoskeleton system.

$$
M_{t} s \dot{x}=F h+F e x-M t g+F d
$$

where $M_{t}$ is the total mass and equal to $M_{p}+M_{h}+M_{e x}$, $g$ is the gravity constant, and $F_{d}$ is an external disturbance force. Assuming that the mechanical actuator can be set as a force-based actuator (e.g., current control in an electric motor directly controls the shaft torque), that is, $\mathrm{F}_{e x}=\mathrm{K}_{\mathrm{ex}} \mathrm{i}_{\mathrm{ex}}$ where $\mathrm{K}_{\mathrm{ex}}$ is the force constant and $\mathrm{i}_{\mathrm{ex}}$ is the input drive signal.

By defining the desired human admittance, $\mathrm{Y}_{\mathrm{h}}{ }^{\text {des }}$, as

$$
Y_{h}^{d e s}=\left.\frac{\dot{x}}{F_{h}}\right|_{F d^{\prime}=0}
$$

where $\mathrm{F}_{\mathrm{d}^{\prime}}=\mathrm{F}_{\mathrm{d}}-\mathrm{M}_{\mathrm{t}} \mathrm{g}$, the desired human admittance can be thought of as the amount of force a human operator has to apply to achieve a given motion velocity. One would like this admittance to be close to a user specified mass and viscous force value that is limited only by power and bandwidth bounds. If one could achieve an arbitrary human admittance such as 


$$
Y_{h}^{d e s}=\frac{1}{M_{e f f} s+K_{\text {veff }}}
$$

where $M_{\text {eff }}$ is the effective mass and $K_{\text {veff }}$ is associated with the effective viscous force, then a detailed understanding of the human neuromuscular control system is unimportant since humans already know how to respond to these environmental forces. To achieve force amplification, an outer control loop will generate an error signal, $\mathrm{E}$, as shown in Fig. 12, where $\mathrm{K}_{\mathrm{h}}$ is the force amplification factor. The goal of the controller is to drive the error term to zero creating a relationship between the human force and the exoskeleton force by the force amplification factor.

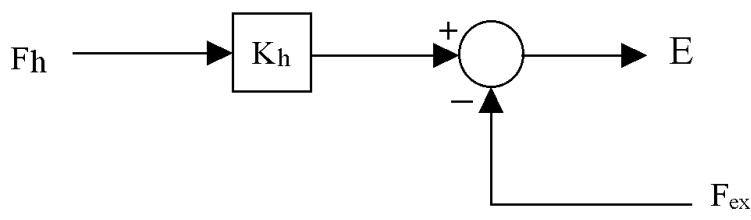

Fig. 12. Outer force control loop.

The remaining issue is the mapping of the error signal, $\mathrm{E}$, to the drive signal, $\mathrm{i}_{\mathrm{ex}}$. One possible control topology is shown in Fig. 13, where the controller can be represented as

$$
i_{e x}=K_{c 2}\left[G_{c 1}\left(K_{h} F_{h}-F_{e x}\right)-K_{p} \frac{\dot{x}}{s}\right]
$$

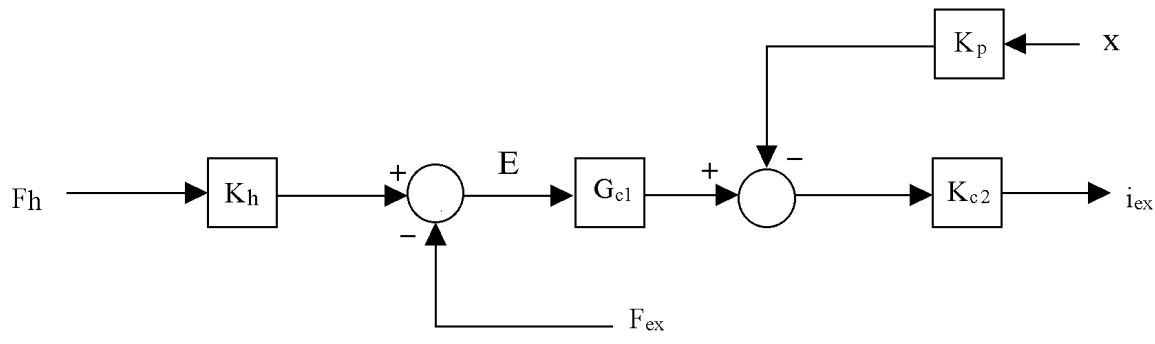

Fig. 13. Exoskeleton controller.

From the combined physical system and controller, the actual admittance of the exoskeleton, $\mathrm{Y}_{\mathrm{h}}{ }^{\mathrm{ex}}$, as felt by the human operator, can be shown to be

$$
\mathrm{Y}_{\mathrm{h}}^{\mathrm{ex}}=\left.\frac{\dot{\mathrm{x}}}{\mathrm{F}_{\mathrm{h}}}\right|_{\mathrm{Fd}^{\prime}=0}=\frac{\mathrm{s}\left[1+\left(1+\mathrm{K}_{\mathrm{h}}\right)_{\left.\mathrm{G}_{\mathrm{c} 1} \mathrm{~K}_{\mathrm{c} 2} \mathrm{~K}_{\mathrm{ex}}\right]}{ }^{2}\left(1+\mathrm{G}_{\mathrm{c} 1} \mathrm{~K}_{\mathrm{c} 2} \mathrm{~K}_{\mathrm{ex}}\right)+\mathrm{K}_{\mathrm{p}} \mathrm{K}_{\mathrm{c} 2} \mathrm{~K}_{\mathrm{ex}}\right.}{\mathrm{M}}
$$

If $\mathrm{G}_{\mathrm{c} 1}=1 / \mathrm{s}$ and the $\mathrm{K}_{\mathrm{c} 2}$ gain is made large enough (this is where a careful overall design is critical), then it can be shown that over the user-specified frequency range, the actual admittance felt by the human operator is 


$$
Y_{h}^{e x}(j \omega) \cong-\frac{1+K_{h}}{M_{t} s+K_{p}}
$$

This shows that the effective mass is $M_{\text {eff }}=M_{t} /\left(1+K_{h}\right)$ and the effective viscous coefficient is $\mathrm{K}_{\text {veff }}=\mathrm{K}_{\mathrm{p}} /\left(1+\mathrm{K}_{\mathrm{h}}\right)$. By controlling the value of force amplification gain $\mathrm{K}_{\mathrm{h}}$ and the feedback gain $\mathrm{K}_{\mathrm{p}}$, arbitrary amounts of effective inertia and viscous friction forces can be felt by the human operator. As an example, say that we want the human operator to feel only his or her mass and none of the payload or the exoskeleton system mass, then the amplification gain would have to be $K_{h}=\left(M_{e x}+M_{p}\right) / M_{h}$. By increasing the force amplification even further, a portion of the human operator mass can also be reduced by energy provided to the exoskeleton actuator.

Likewise, it can be shown that the gravitational and disturbance forces that are reflected back to the human operator, called the overall disturbance force (i.e., $F_{d}$ ), and assuming that the exoskeleton system is not moving, is related to the human force by

$$
\left.\frac{\mathrm{F}_{\mathrm{d}^{\prime}}}{\mathrm{F}_{\mathrm{h}}}\right|_{\dot{\mathrm{X}}=0} \cong \frac{1}{1+\mathrm{Kh}}
$$

over the user-specified frequency range. This indicates that force reflection is simply a function of the amplification gain and is similar to the ratios of the effective mass and viscous forces.

For state 2, where the exoskeleton system impacts the ground, the only difference between state 2 and state 1 is that the initial velocity is assumed to be nonzero. Equation (7) can be modified to show this change

$$
M t s \dot{x}=F h+F e x-M t g+F d+M t \dot{x}(0)
$$

(Note that this equation is in the s-domain and not the time domain). In addition, the disturbance force is modified to

$$
F_{d^{\prime}}=-M t g+F d+M t \dot{x}(0)
$$

All the results for state 1 can now be applied to state 2 , while the only change, the additional momentum force, is because of a nonzero impact velocity. This impact force will be felt by the human operator, but at a reduced level, and can be further reduced by means of suitable mechanical compliance in the exoskeleton structure.

If one examines how the disturbance force can affect the exoskeleton velocity, it can be shown through reasoning similar to the discussion for state 1 , that

$$
\left.\frac{\dot{\mathrm{x}}}{\mathrm{F}_{\mathrm{d}^{\prime}}}\right|_{\mathrm{Fh}=0} \cong \frac{1}{\mathrm{Mt} \mathrm{s}+\mathrm{Kp}}
$$


over the user-specified frequency range, where the benefits of the computer-controlled viscous damping term $\mathrm{K}_{\mathrm{p}}$ becomes clear; it dissipates the impact force. Impact forces can be damped to specific target values by the controller; in addition, the mechanical structure can be designed to provide further system damping.

For state 3, where the exoskeleton is off the ground, all ground reactions are obviously zero which forces the governing dynamic equations represented originally by Eq. (7) to change to the following:

$$
\mathrm{Mts} \dot{\mathrm{x}}=-\mathrm{Mt}_{\mathrm{t}} \mathrm{g}+\mathrm{Fd}+\mathrm{Mt} \dot{\mathrm{x}}(0) \text { and } \mathrm{F}_{\mathrm{h}}+\mathrm{F}_{\mathrm{ex}}=0
$$

(Note that these equations are in the s-domain and not the time domain in regard to the initial velocity of the system). The actuator for this 1-DOF exoskeleton system cannot affect the trajectory of the system, and the human and exoskeleton forces add up to zero. The exoskeleton controller will try to force tracking between the human force and the exoskeleton force, which implies that the effective human force will be about zero (depending on the tracking performance of the controller). When the exoskeleton system is off the ground, the human feels almost no force and cannot affect the trajectory of the system. This is true only for this simple case, where only a 1-DOF example is being considered. For a two-legged system, the leg on the ground would provide the reaction force for the leg that is off the ground.

In summary, a 1-DOF system has been examined to study the feasibility of using a force-based control system to implement performance enhancement. An overview of controller issues, including force sensing, creating a relationship between the human and exoskeleton forces, the use of the human capability to respond to environmental forces, and the damping of impact forces have been addressed. It has been shown that by means of force-based feedback, the effective mass and disturbance and viscous forces as felt by the human operator of an exoskeleton, can be readily controlled. Performance is intrinsically limited only by the mechanical bandwidth and power limitations of the actuators, and the mechanical structure. While examined with a 1-DOF case, these concepts should readily extend to the multiple-DOF case.

\section{SAFETY AND FAULT DETECTION CONCEPTS}

Safety will be a prime concern in the eventual deployment of any exoskeleton. A common failure scenario in a hydraulic servomechanism is the failure of either the servovalve, drive electronics, or sensors (say a positional sensor like a resolver) causing a significant flow of fluid to the hydraulic actuator. Detection of this type of fault has to occur quickly because of the highbandwidth of an exoskeleton, which could result in significant motion within $150 \mathrm{~ms}$. For example, the required dynamic response could result in $80^{\circ}$ movement of the knee in $150 \mathrm{~ms}$ or less. The best-case human-reflex response time is 110 to $150 \mathrm{~ms}$. Thus, there is a significant potential for injury without adequate fault detection and response capability. Because of the human reaction times, it is unreasonable to expect that an operator could activate an emergency stop button in the time required to prevent injury in the worst-case scenario. 
The general approach to error detection is through model-based anticipatory and trendforecasting schemes (such as Kalman predictive filtering), which can detect a system error during system transients (Tylee, 1983). Unfortunately, conventional methods cannot distinguish between a fault and system disturbance because of the short decision times available when a failure occurs and the unpredictable nature of disturbances acting on an exoskeleton (such as thermal drift in the drive electronics, mechanical vibrations, impact forces, etc.). This explains why such systems are not readily commercially available.

ORNL's approach has been to break apart the disturbance forces acting on the system (such as thermal drift in the drive electronics, mechanical vibrations, impact forces, etc.) from the overall nonlinear system response caused by a fault. Preliminary work indicates that this approach of partitioning of these forces on a real system can achieve response times around $200 \mathrm{msec}$ (see Fig. 14). ORNL has demonstrated this approach and $200 \mathrm{msec}$ response times on the Next Generation Munitions Handler (NGMH) system. The response times of the command valves are currently limited around $100 \mathrm{msec}$ by the inductance-resistance time-constants. The eventual goal of the safety-fault detection system is to reduce the response times to as close to a $50 \mathrm{msec}$ goal as possible.
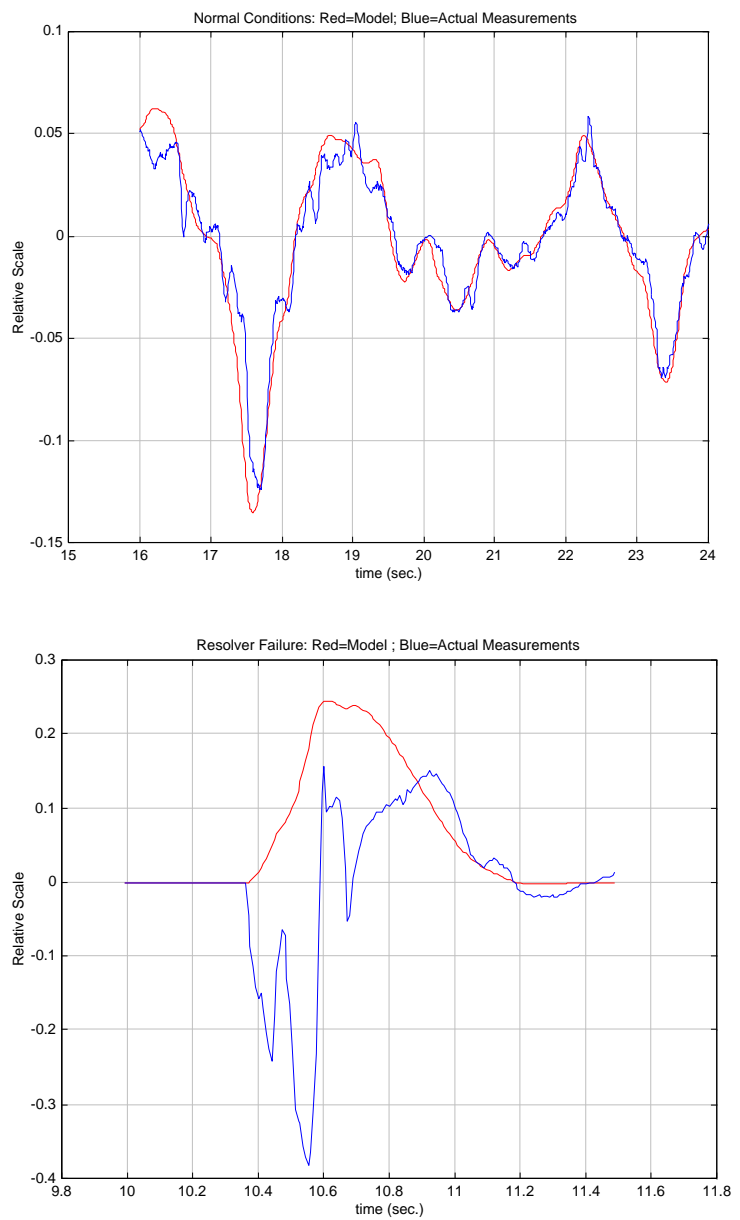

Fig. 14. NGMH fault detection (normal operation and sensor failure). 
Analysis of the current system indicates that for a hydraulic system, using special shut-off valves, which have reduced inductance-resistance time-constants, can significantly reduce the response time. Other factors, such as faster processing capabilities have a much less significant impact. Further research is needed regarding issues relating to system safety and approaches for further reducing response times. Current models and simulations, verified by data from an operating system, provide a starting point for more detailed study of approaches to ensuring system safety.

\section{DESIGN CONCEPTS}

The design of the exoskeleton structure must address the fact that the structure's primary function is to support the payload and provide the mechanical interface with the operator, while at the same time, the function must be transparent to the operator and enable overall system energy efficiency. In essence, the exoskeleton is wrapped around the operator and supports the payload as well as its own load with the objective of minimizing disturbances exerted on the operator. Two basic design approaches will be discussed. The first is based on designing the exoskeleton to track the human operator joint by joint. The second approach is based on tracking the limb end-point (foot or hand), but not necessarily matching each joint. Regardless of the approach taken, the design of the exoskeleton should be highly anthropomorphic. While the overall form of the exoskeleton may not differ dramatically based on the approach taken, system complexity, including, the number and location of joints, the number and location of attachment points, and the control system complexity, will all be affected.

In comparing these two approaches, consideration of some of the intricacies of human anatomy must be taken into account. First, the human arm and leg have redundant joints; thus, there are multiple joint configurations for each unique hand and foot position and/or orientation. To replicate this capability adds degrees of freedom and increasing system complexity. A study by the Army Research Laboratory detailing requirements for an exoskeleton suggests a minimum number of DOF (Table 6). Note that the recommendation includes 6 DOF for the leg (it does not include ankle abduction-adduction) and $7 \mathrm{DOF}$ for the arm. The addition of a redundant degree of freedom will obviously increase the overall complexity of the control system.

Table 6. Minimum DOF for exoskeleton joints (Crowell, 1995).

\begin{tabular}{|l|l|l|}
\hline Joint & DOF & Description \\
\hline \hline Foot & 1 & Extension for metacarpophalangela joint \\
\hline Ankle & 1 & Flexion-extension \\
\hline Knee & 1 & Flexion \\
\hline Hip & 3 & Flexion-extension, abduction-adduction, medial-lateral rotation \\
\hline Pelvis & 3 & Coronal, sagittal, and transverse plane rotations \\
\hline Spine segments & 3 & Flexion-extension lateral flexion, rotation \\
\hline Shoulder & 3 & Flexion-extension, abduction, medial-lateral rotation \\
\hline Elbow & 2 & Flexion, forearm pronation-supination \\
\hline Wrist & 2 & Flexion-extension, abduction-adduction \\
\hline
\end{tabular}


Co-locating joints such that both the human joint and the exoskeleton joint rotate about a common axis is difficult, especially at joints with multiple degrees of freedom, such as the hip, shoulder, wrist, and ankle. With a non-co-located joint, the likelihood of the exoskeleton impeding the motion of the operator is increased. This increases the difficulty of the design, especially when combined with the need to accommodate a broad range of operator sizes. The addition of a redundant joint, while adding complexity, especially to the control system, can aid in avoiding configurations where the exoskeleton does in fact impede the operator.

To follow or track, the human operator on a joint-by-joint basis requires attachment and sensing at or near the joint. For example, to track the knee, attachment above and below the knee would be required. As joint-by-joint tracking implies a position-position control loop, position sensing of both the human and exoskeleton joints would also be required. Complicating this is the fact that the centers of rotation for human joints, such as the knee, are not fixed. Replicating these types of joints mechanically is difficult, and the likely result is tracking errors, which will have some impact on the interface at the attachment points.

The second approach, tracking the limb end-point, has advantages over the joint-by-joint tracking approach. First, attachments are not required at each joint. In particular, no attachment is required for the elbow and knee. The number of degrees of freedom can be limited to 6 for each limb, thus reducing complexity and weight. Accurately tracking of each individual joint is not an issue, eliminating the need to accurately sense the position of each human joint and to accommodate the motion of complex joints such as the knee. Significant reduction in mechanical complexity is achieved in this approach at the expense of increased complexity of the control system. The remaining discussion is based on the results of these comparisons, in an effort to address other design issues affecting feasibility.

\subsection{Structure}

Design of a transparent exoskeleton is affected by many parameters such as response bandwidth, sensing points, soft-tissue interfaces, and amplification schemes, in addition to key structural parameters, including kinematics, load-transfer points, and the determination of actuated versus non-actuated joints. While the design of the exoskeleton should be highly anthropomorphic, a 1:1 correspondence between each of the exoskeleton and operator joints is not necessary. It is essential, however, that these joints be located in as close of proximity as possible, although not necessarily co-located.

Co-locating joints, such as the hip and wrist, were evaluated to determine the design trade-offs related to the structure. The most significant advantage of co-locating the joints is reduced tracking errors. The trade-off is in the increased complexity, as can be seen in the co-located hip joint as seen in Fig. 15. A special configuration that allows for remote centers of rotation (which are co-located with the body's center of rotation), limits the range of motion achievable without interfering with the body, and greatly increases the difficulty in the design of bearings. The fact that the hip requires the simultaneous co-location of three DOF, adds tremendously to the mechanical complexity in achieving the desired range of motions. Figure 15 shows the medial and lateral rotations, as well as the hip abduction. It can be seen in the hip abduction (third frame) that the motion causes an interference with the body. After investigating a number of options, it became apparent that co-locating a joint as elaborate as the human hip was extremely 
difficult, with complexity that rendered such a design impractical. A non-co-located hip design, with linear actuators, is shown in Fig. 16. It should be noted that these figures represent concepts and that further detailed design would obviously be required.
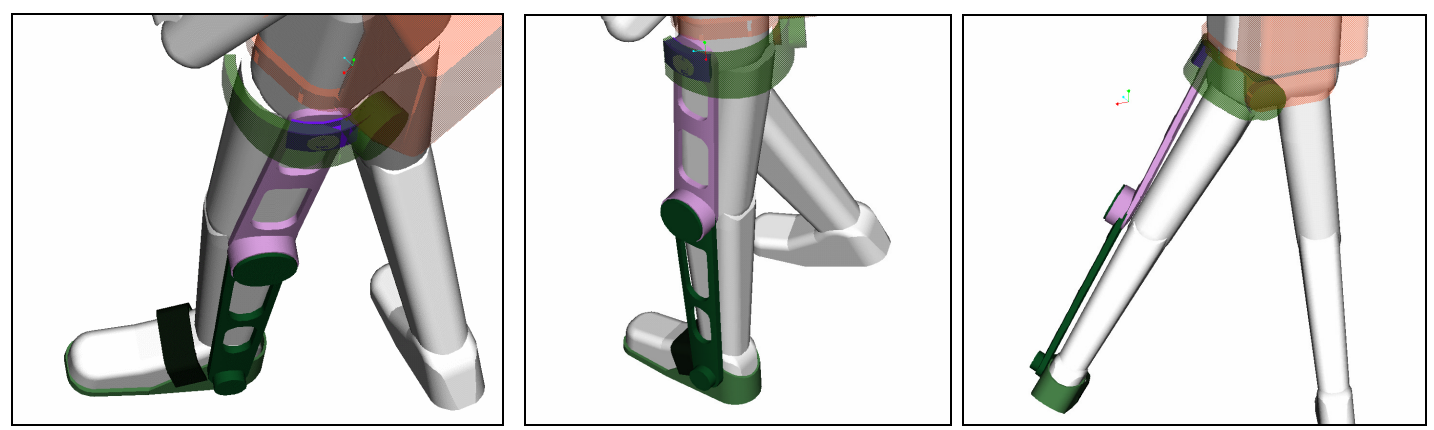

Fig. 15. Co-located hip.

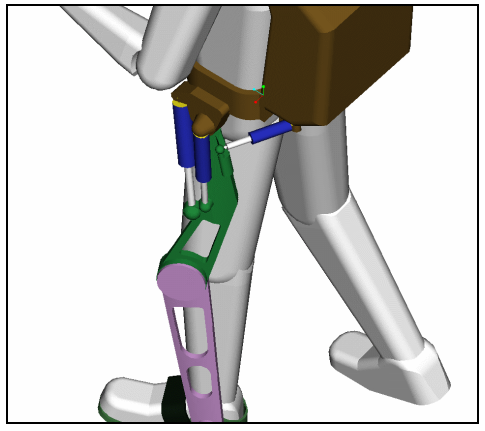

Fig. 16. Non-co-located hip with linear actuators.

Co-locating of joints is also an issue with the arm design as well. Due to complexity and range of motion limitations, the shoulder does not lend itself to co-location, similar to the hip. However, examination of the elbow joints forearm pronation-suppination, which gives the wrist roll type of motion, indicates that co-locating of that joint can be accomplished while simplifying the design (Fig. 17).
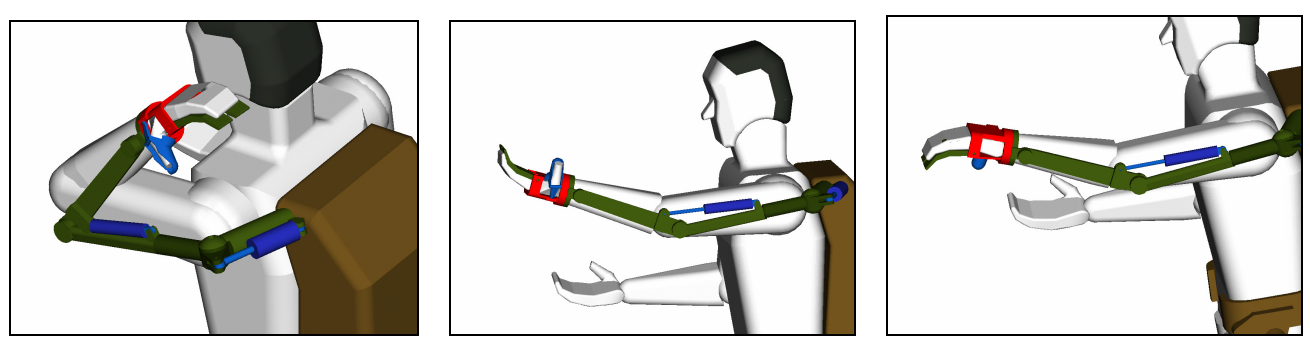

Fig. 17. Shoulder and arm structure.

Table 6 lists a minimum of 6 DOF per leg. A couple of points can be made concerning the number of DOF. It may be tempting to eliminate the hip medial-lateral rotation to simplify the 
design, as has been done in some proposed concepts. This, however, introduces a complication that would require further evaluation. Without this DOF and likewise, without the ankle abduction-adduction, the foot is constrained to remain in the same plane as the leg. This has implications with regards to changing direction, and at the very least will require slipping of the foot and may in fact alter the normal manner in which one changes direction.

Joint design type was also investigated. The issue is to determine where to use rotary or linear actuators. Compactness of the design and range of motion are the determining criteria. The selection of either rotary or linear actuators is highly dependent on the joint. In general, rotary actuators appear to be more applicable to joints where more than $90^{\circ}$ range of motion is required. Linear actuators have an advantage with respect to the ease of measuring force. The knee flexion, for instance, could be done using either type of joint. The ankle flexion-extension, although it is less than $90^{\circ}$ may be more appropriately done with a rotary joint (Fig. 15). Ball and socket joints such as the hip in Fig. 16 would require linear joints.

As stated previously, minimization of power and energy requirements is crucial to the development of a truly "fieldable" exoskeleton system. An emphasis on optimizing the design of the structural elements to minimize system weight is an important aspect in the overall systems approach. The criteria for sizing the structural elements must take into consideration not only stresses, but structural stiffness as well. For the anticipated load range, stiffness is the determining factor in the sizing of the structural elements. Thus, minimizing the size of structural elements must be traded off with the requirement of maintaining structural stiffness.

While detailed modeling and analysis will be required to optimize this trade-off, preliminary analysis indicates that adjustable aluminum channel members can be used for the upper and lower links, respectively. Based on this analysis, assuming a $136 \mathrm{~kg}$ (300 lb) payload and a minimum structural natural frequency of $10 \mathrm{~Hz}$, an approximate weight for the structural system was calculated to be on the order of $12 \mathrm{~kg}$ (excluding actuators). The payload included the weight of the exoskeleton, assumed to be on the order of $32 \mathrm{~kg}(70 \mathrm{lb})$ and an effective payload of $105 \mathrm{~kg}(230 \mathrm{lb})$. The effective payload, which could take the form of either a backpack or an item manipulated using the exoskeleton arms, was used to size both the arms and the legs, which must transmit the load in either case. A study on the effects of increased payload showed that doubling of the payload had the affect of increasing the approximate weight of the structure by about $40 \%$ (excluding actuators).

For an exoskeleton to move from the laboratory to the field, the structure must be adjustable to accommodate a wide range of operator sizes. The goal should be able to accommodate from the $5 \%$ female to the $95 \%$ male. Adjustments will be required for both the upper and lower leg and arm links. Adjustment will also be required to accommodate for variances in torso proportions as well.

\subsection{Attachment}

Attachment of the exoskeleton is extremely difficult because of the close coupling required between the machine and the operator and the sensitivity of soft tissues, which are susceptible to bruising and damage with pressures as low as $0.1 \mathrm{~atm}$ over a few hours. There are considerable knowledge and experience embedded in the fields of orthotics and prosthetics, which have been 
addressing the problems of applying significant forces to the skeleton while keeping skin loading to acceptable levels.

As stated previously, the exoskeleton should be highly anthropomorphic - that joints should be located in as close of proximity as possible, although not necessarily co-located and that a 1:1 correspondence between each of the exoskeleton and operator joints is not necessary. Therefore, the number of attachment points can be kept to a minimum by attaching at the limb extremities (feet and hands) and at the waist and shoulder. Thus, the leg or arm would be controlled based on the force input at the extremities as opposed to matching positions of each joint. By minimizing the number of attachment points, the total number of required DOF and actuators can be reduced, and the difficult task of mechanically replicating the motions of the human knee, which does not have a fixed center of rotation, can be avoided. The trade-off for simplifying the mechanical design is increased difficulty in the design of the control system (i.e., going from a joint-to-joint to a Cartesian control scheme).

It is important to provide a reliable and comfortable attachment at the human foot to the exoskeleton (Fig. 18). In this concept, soldiers outfitted for exoskeleton augmentation will wear boots that have built-in rapid-release attachment points. The boots will permit normal bending of the foot at the toes and will not create any additional human-tissue contact points. When not attached to the exoskeleton, the boots will feel and perform like ordinary boots. The coupling at the foot includes sensing of both the operator and the total system forces. These forces will be measured using multi-axis, force-torque sensors. The design will ensure that forces transmitted from the human foot to the exoskeleton can be accurately and unambiguously measured. The role of this force sensor was discussed in greater detail in the control section.

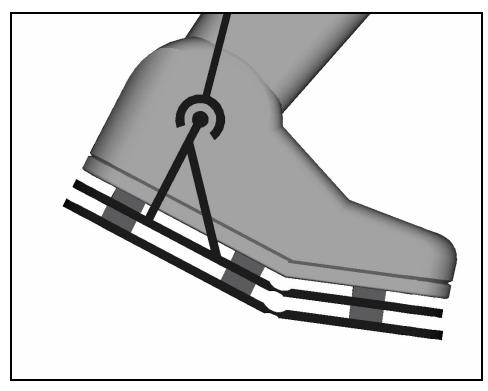

Fig. 18. Foot attachment schematic.

Attachment at the waist and shoulder areas would use a belt and shoulder straps, which are normal contact pressure areas. A major design issue would be to maintain comfort and acceptable loading over extended periods of time.

\subsection{Conceptual Enhancements}

Some additional conceptual ideas that could enhance the design of an exoskeleton and thus potentially increase the likelihood of successfully developing an exoskeleton have been considered: first, the concept of using passive joints to reduce system complexity, and next, the concept of reconfiguration and multiple mode operation. 


\subsubsection{Passive Joints}

While this study is focused on determining the feasibility of a powered exoskeleton, there may be opportunities to use passive joints as opposed to actuated joints in certain instances. Obviously, there is a significant advantage in weight and energy savings and reliability and cost in using passive joints where appropriate to simplify the system. While the actual determination of the joints that could be made passive would require more detailed analysis than the scope of this study allows, there are two joints that stand out as possible candidates. The metacarpophalangeal joint, as seen in Fig. 15, is the most likely candidate to be made passive. The hip-rotation joint is another possibility.

\subsubsection{Reconfiguration and Multiple Mode Operation}

The possibility of a modest reconfiguration of the system to allow a low power mode of operation was also investigated. In particular, a lower power, ballistic-type walking mode was investigated. Such mode would be advantageous for tasks such as long marches and could enhance operating times. Emulating a straight-leg ballistic mode is shown in Fig. 19. In this mode, the knees would essentially be locked and a thigh prismatic joint would be used to lengthen and shorten the legs, which would be moving with a pendulum type motion. Obviously, in such a mode close tracking of the knee is not a concern, but conservation of energy is the primary motivation. The trade-off for energy efficiency is the addition of the prismatic joint.

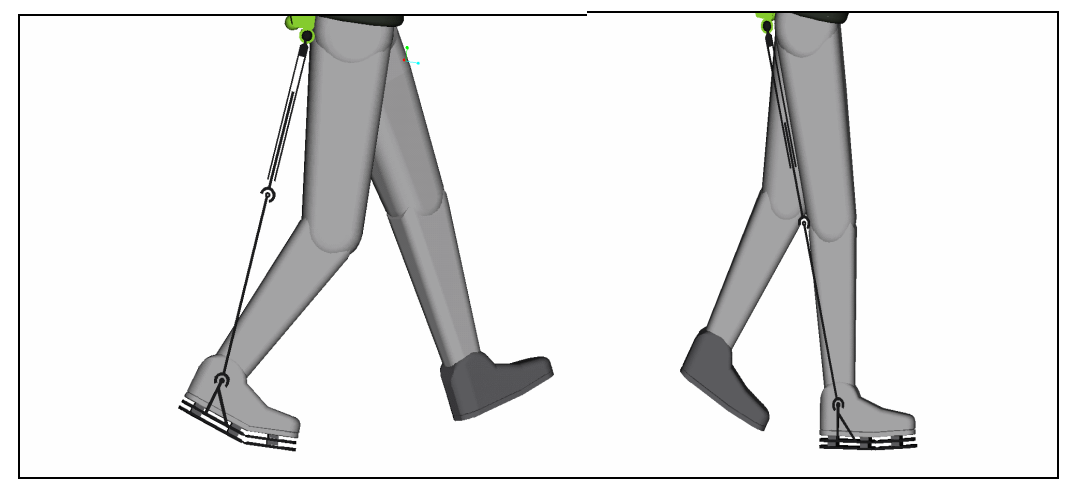

Fig. 19. Straight-leg ballistic mode.

The addition of a thigh prismatic joint (Fig. 20) could add other advantages. These include the minimization of tracking errors between the operator and exoskeleton legs, thereby reducing the risk of the exoskeleton impeding operator motion and allowing for a "tighter fitting" exoskeleton. The prismatic joint also compensates for pelvic-tilt-type motions, which were not easily accommodated with rotational joints. 

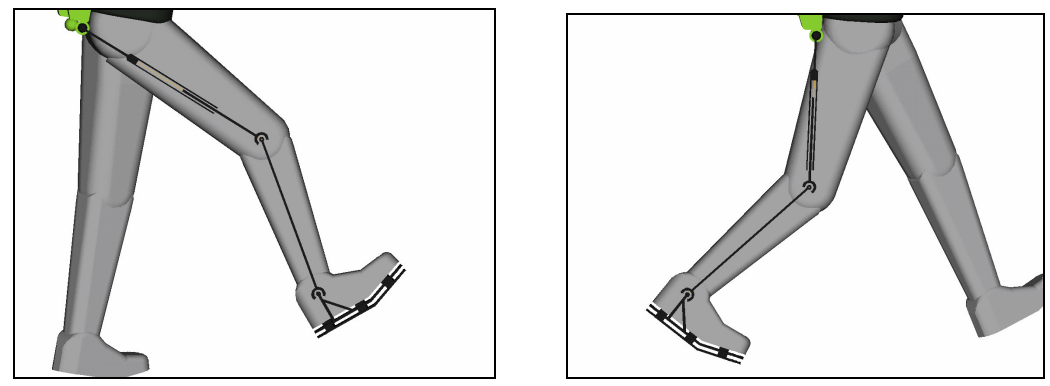

Fig. 20. Leg structure schematic demonstrating thigh prismatic joint.

\section{RECOMMENDATIONS}

The purpose of this study and report are to address the issue of feasibility of building an exoskeleton for human performance augmentation. Previous efforts, while demonstrating progress and enhancing knowledge, have not approached the level required for a fully functional, fieldable system. It is doubtless that the technologies required for a successful exoskeleton have advanced, and some of them significantly. The question to be addressed is have they advanced to the point of making a system feasible in the next three to five years? In this study, the key technologies required to successfully build an exoskeleton have been discussed. Based on the present state of the art and the possibility for near-term enhancements, we believe that building a fully functional, fieldable prototype system is feasible, but with a certain amount of inherent risk. Recent advances in fuel cell, battery, and super capacitor technology make the possibility of an efficient hybrid power source feasible. In addition, on-going work on internal combustion engines, in particular micro turbine generators and small diesel engines offer potential near-term power sources that could be viable for exoskeleton applications. For actuation, it appears that hydraulics is the best candidate for the exoskeleton project at this time, but both the piezoelectric and the magnetostrictive materials hold great promise and should be investigated further. Recent advancements in human amplification systems provide the foundation for a control approach based on limb end-point tracking using force sensing and control at the attachment points, with the inherent advantage of minimizing contact points and the difficulties associated with joint by joint tracking. In summary, the current state of the art of technology provides the basis for the contention that building an exoskeleton within the next three to five years is feasible.

\subsection{Development Approach}

While there are many important aspects in successfully developing an exoskeleton, efficient power and energy sources and actuation are critical. A successful overall approach must emphasize the optimization of energy efficiency, both at the global mission scale and at the system component level, while also providing a design that is ergonomic and as transparent as possible. Analysis of militarily significant missions of interest shows that the soldier payloads, duration and tempo of operations, movements and limb motions, and corresponding energy and power demands on the components of an exoskeleton will vary greatly, depending upon the particular mission. To accommodate these significant variations in power and energy needs and mission-related requirements, it is recommended that an energy-management control loop be a part of the exoskeleton and a re-configurable kinematics structure should be further evaluated. This re-configurable structure would allow the soldier to directly switch between modes of 
operation best suited for either long-range march and/or backpack transport missions or swift, rapid, highly agile but energy-consuming, combat-type missions. An added benefit of these features is that they provide the soldier the ability to make trade-offs with respect to operational parameters such as range, fuel reserves, operation of transported electric devices and accessories, and the degree of strength and mobility enhancement (i.e., the amplification ratio and amplification means). These trade-offs allow the soldier to best adapt the use of the exoskeleton to the evolving mission conditions.

Another recommended approach is the use of a Cartesian force mode of operation for a structural configuration based on limb end-point tracking. Human knee and elbow joints are not simple pin joints, but are complex joints with a changing instantaneous center of rotation, with motion characteristics that are extremely variable between individuals. Furthermore, studies of orthotics and principles of interfacing with human tissues indicate that pressures as low as $70 \mathrm{~mm} \mathrm{of} \mathrm{Hg}$ ( 0.1 of an atm) can significantly damage skin and soft tissues in a few hours. Potential "pinching" of the tendons (e.g., in the back of the upper knee) and the large contraction and deforming of the muscles in the vicinity of the knee and elbow makes sensing braces or attachment of the exoskeleton near the knee or elbow extremely difficult and undesirable. These also make joint-to-joint motion-tracking control of the knee or elbow based on displacement sensing of these joints likely to fail in meeting the objectives of user comfort and non-impeding physical enhancement. Thus, it is recommended that interfaces should be at the foot, waist, upper-back and/or shoulder and wrist, which are natural pressure and attachment areas for humans (shoe, belt, backpack straps, watch, and/or gloves). Furthermore, a Cartesian control scheme should be used based on force sensing at these attachment points, and that provides for close tracking of the body, knees, and elbows without direct attachment.

Preliminary motion modeling and analysis indicates that the average power and energy needs are mission dependent and can vary by more than one order of magnitude. For example, about $150 \mathrm{~W}$ are required when walking with 350-lb payloads (backpack, exoskeleton, and fuel) to peaks of the order of $2 \mathrm{~kW}$ when climbing stairs or performing quick, deep, knee-bending motions. A variety of options exist to effectively meet the exoskeleton power and energy demands, including hybrid systems using multiple sources. Additional requirements of safety (no hazardous, explosive, or toxic materials, and no high-pressure lines, etc.), stealth (silent, low-temperature, no exhaust fumes, etc.), and scalability, as well as the potential for significant near-term improvement in the basic component technologies through DARPA or other agencies' (e.g., U.S. Department of Energy) programs were considered. Based on these requirements, a hybrid system consisting of a chemical reaction (sodium borohydride, $\mathrm{NaBH}_{4}$ )-fueled hydrogen generator feeding a Proton Exchange Membrane (PEM) fuel cell, with a power storage and transient handling subsystem consisting of rechargeable NiMH batteries and/or super capacitors, is recommended. Electrical power is used to run the control processors, sensors and actuators, as well as possibly other non-exoskeleton-related electronic devices and accessories. Based on bandwidth requirements, safety considerations, and power densities, hydraulic actuators are recommended. There are two possibilities with regards to hydraulic actuation. The first is a low-risk, conventional hydraulics approach using high-performance servo valves. The second approach, with a higher risk, is based on piezo-based hydraulic pumps distributed over the structure with corresponding hydraulic actuators and hydrostatic control. Hydrostatic control (as opposed to pressure regulated systems in conventional servo valve hydraulic designs) allows 
high actuation efficiencies at high bandwidth, as well as sealing of the piezo-pump/cylinder assemblies (i.e., no external hydraulic pressure lines). Use of water-based hydraulic fluids offers the opportunity for additional safety. While higher risk, this piezo-based hydraulics approach appears to hold the most promise. 


\section{REFERENCES}

Amendola, S. C., et al., 2000, An Ultrasafe Hydrogen Generator: Aqueous, Alkaline Borohydride Solutions and Ru Catalyst, Journal of Power Sources, 85, 186-189.

Andersen, B. W., 1967, The Analysis and Design of Pneumatic Systems, Krieger Publishing Co., Malabar, Florida.

Andriulli, J. B., et al., November 1999, Advanced Power Generation Systems for the $21^{\text {st }}$ Century: Market Survey and Recommendations for a Design Philosophy, ORNL/TM-1999/213, Oak Ridge National Laboratory, Oak Ridge, Tennessee.

Crowell, H. P., July 1995, Human Engineering Design Guidelines for a Powered, Full Body Exoskeleton, Army Research Laboratory, ARL-TN-60.

Dowling, K., January 1997, Power Sources for Small Robots, CMU-RI-TR-97-02, Carnegie Mellon University.

Chou, C. P. and Hannaford, B. (1996):Measurements and Modeling of McKibben Pneumatic Artificial Muscles. IEEE Transactions on Robotics and Automation. 12(1):90-102.

Hirschenhofer, J.H., D. B. Stauffer, R. R. Engleman, and M. R. Klett, 1994, Fuel Cell Handbook, Business/Technology Books for the U.S. Department of Energy.

Heywood, John B., 1988, Internal Combustion Engine Fundamentals, McGraw-Hill, New York.

Hollerbach, J. M., I. W. Hunter, J. Ballantyne, 1992, "A Comparative Analysis of Actuator Technologies for Robotics." pp. 299-342 in The Robotics Review 2, ed. O. Khatib, J. Craig, T. Perez, The MIT Press, Cambridge, Massachuesettes.

Kellogg, R. and A. Flatau, March 1999, "Blocked Force Investigation of a Terfenol-D Transducer," pp. 184-195 in Proc. SPIE Conf. on Smart Structures and Integrated Systems, Newport Beach, California.

Newton, D. V., J. A. Main, E. Garcia, and L. Massengill, February 1996, "Piezoelectric Actuation Systems: Optimization of Driving Electronics," pp. 259-266 in Proc. of SPIE's 1996 North American Symposium on Smart Structures and materials: Smart Structures and Integrated Systems, Vol. 2717, San Diego, California.

McMahon, T. A., Summer 1984, "Mechanics of Locomotion," The International Journal of Robotics Research, 3 (2), 4-28.

Merritt, H. E., 1989, Hydraulic Control Systems, John Wiley and Sons, New York.

Miller, T. J., 1989. Brushless Permanent Magnet and Reluctance Motor Drives, Oxford University Press, Oxford, UK. 
Nasser, K., D., J. Leo, and H. H. Cudney, 2000, Compact Piezohydraulic Actuation System, SPIE Paper Number 3991-41: Annual Symposium on Smart Structures and Materials.

Theis, T. J., J. C. Conklin, J. F.Thomas, and T. R. Armstrong, March 2000, "Comparison of Prime Movers Suitable for USMC Expeditionary Power Sources," ORNL/TM-2000/116, Oak Ridge National Laboratory, Oak Ridge, Tennessee.

Thomas, S., and M. Zalbowitz, 1999, "Fuel Cells - Green Power", LA-UR-99-3231, Los Alamos National Laboratory, Los Alamos, New Mexico.

Tylee, L., March 1983, "On-Line Failure Detection in Nuclear Power Plant Instrumentation," IEEE Trans. Automat. Contr., AC-28, 406-415. 
ORNL/TM-2000/256

\section{INTERNAL DISTRIBUTION}

1. J. F. Birdwell

2. J. B. Chesser

3. A. Clemons

4. D. L. Conner

5. D. C. Haley

6. J. N. Herndon

7-11. J. F. Jansen

12. R. F. Lind

13. L. J. Love

14. ORNL Central Research Library

15. ORNL Laboratory Records

16-20. F. G. Pin

21-25. B. S. Richardson

26. S. L. Schrock

\section{EXTERNAL DISTRIBUTION}

27-31. Dr. Ephrahim Garcia, Defense Advanced Research Projects Agency, 3701 North Fairfax Drive, Arlington, VA 22203-1714. 